\title{
Semiactive Control of High-Speed Railway Vehicle Suspension Systems with Magnetorheological Dampers
}

\author{
Yingying Liao $\mathbb{D},^{1,2}$ Yongqiang Liu $\left.\mathbb{D}\right)^{2,3}$ and Shaopu Yang $\mathbb{D}^{2,3}$ \\ ${ }^{1}$ School of Civil Engineering, Shijiazhuang Tiedao University, Shijiazhuang, Hebei, China \\ ${ }^{2}$ State Key Laboratory of Mechanical Behavior in Traffic Engineering Structure and System Safety, Shijiazhuang, Hebei, China \\ ${ }^{3}$ School of Mechanical Engineering, Shijiazhuang Tiedao University, Shijiazhuang, Hebei, China
}

Correspondence should be addressed to Yongqiang Liu; liuyq@stdu.edu.cn and Shaopu Yang; yangsp@stdu.edu.cn

Received 26 April 2019; Revised 6 September 2019; Accepted 29 September 2019; Published 6 November 2019

Academic Editor: Salvatore Russo

Copyright ( $) 2019$ Yingying Liao et al. This is an open access article distributed under the Creative Commons Attribution License, which permits unrestricted use, distribution, and reproduction in any medium, provided the original work is properly cited.

Using the magnetorheological (MR) damper model, this paper derives a semiactive suspension model for a high-speed railway vehicle, and a new evaluating method is proposed to analyze the effect of two kinds of time delay existing in control systems on vehicle dynamic performance. The railway vehicle is modeled by a 50 degree-of-freedom (DOF) system which considers the full 6 DOF of each wheelset, bogie, car body, and the pitch angle of each axle box. Several control strategies, sky-hook (SH), accelerationdriven damping (ADD), and mixed SH-ADD, are considered in the semiactive suspension system. To evaluate the effect of these semiactive controls and the different kinds of time delay on the lateral ride index of a high-speed railway vehicle, a 3D surface in a rectangular coordinate system is described. The cross curve between the $3 \mathrm{D}$ surface and a horizontal plane which represents the performance of passive suspension is projected on the $X$ - $Y$ plane, and the area enclosed by the contour line, $X$-axis, and $Y$-axis can be used to evaluate the performance of semiactive controls. The results show that the new method is convenient to evaluate the performance of semiactive control strategies visually when there is more than one kind of time delay.

\section{Introduction}

1.1. Challenges Associated with High-Speed Railway Vehicle Dynamic Performance. A high-speed railway vehicle is a multi-degree of freedom strongly nonlinear mechanical system, and the vibration response of the system is very complex under random railway excitation. The high-speed railway vehicles can reach $380 \mathrm{~km} / \mathrm{h}$ in some railway passenger transport special lines in China [1]. The vibration amplitude and frequency width vary substantially when the speed of railway vehicles is changed from 0 to $380 \mathrm{~km} / \mathrm{h}$. The conventional suspension system in railway vehicles is unable to adapt suitably to the large differences in vibration amplitude and frequency. As a result, the ride comfort of passengers, lateral stability, and safety are severely degraded. Consequently, a semiactive or active-controlled suspension is needed to meet the new demands. Semiactive or active suspension can adjust parameters or output force automatically to restrain the car body vibration according to the real-time status of railway vehicles [2-4].

In active control systems, errors cause unwanted forces acting on the car body or/and bogie frames, which may cause a series of disastrous consequences $[5,6]$. Unlike active control, semiactive control adjusts only the damping coefficient of dampers to adapt to the new need. Even if the semiactive control fails, the suspension system can continue to work in the passive state [7]. Therefore, the safety advantage of semiactive control is clear. In addition, relative to active control, semiactive control costs little energy, responds quickly, and is easily maintained.

Because of the safety, high cost, and long period required, it is challenging to test actual MR dampers in a real railway vehicle running on a real track, especially for theoretical research. Hence, it is necessary to build a semiactive suspension system for high-speed railway vehicles and to conduct complex dynamic simulations computationally. 
1.2. Semiactive Suspension Systems for Railway Vehicles. In studies of semiactive suspension, three main types of vehicle models have been developed, namely, quarter car, half-car, and full-car models, which can be built using SIMULINK, SIMPACK, VI-Rail, or other software. Typically, the quarter car model is used only to research methods of improving the ride comfort of passengers because of its simple structure, and half-car and full-car models are used to characterize other types of dynamic performance, such as lateral stability and running safety. However, most research attention is placed on improving ride comfort or reducing the vibration of the car body, and other dynamics of performance of railway vehicles are typically neglected, although they are important [8-10]. For a running railway vehicle, the most important performance aspect should be safety, particularly when the railway vehicle is running on a curved track. The lateral stability of railway vehicles is also an important factor in evaluating a railway vehicle, and the linear/nonlinear critical speed is the most widely used index. A railway vehicle whose speed exceeds the nonlinear critical speed is generally considered dangerous.

Thus, after control strategies are elucidated for the simple vehicle models, a complex railway vehicle model including the wheel/rail contact subsystem and primary and secondary suspension subsystems can be considered. Using SIMPACK, Chen et al. developed a multibody dynamics model, and a cosimulation analysis of semiactive suspension was conducted in SIMPACK and SIMULINK [11]. An active steering bogie for urban trains was developed by Hwang et al., and the system was simulated by means of a cosimulation with VI-Rail and SIMULINK [12]. In many papers, ride comfort analysis most often constitutes the area of interest; analysis of lateral stability and safety under semiactive control is seldom performed because of the limitations of software, methods, or models.

Since the 1970s, semiactive suspensions have attracted much attention, and some controllable dampers, including electrorheological (ER) dampers and magnetorheological (MR) dampers, have been available for use in semiactive suspensions of railway vehicles [13-15]. Many semiactive control strategies based on measured signals, such as skyhook (SH) [16], ground-hook (GH) [17], acceleration-driven damping (ADD) [18], and hybrid control [19], have begun to be used in simulations and research tools.

The complex dynamics characteristics of MR dampers such as hysteresis loops and magnetic saturation make the models of MR dampers very important. According to their different functions, the models of MR dampers include forward models and inverse models. The commonly used forward model of the Bouc-Wen model and inverse model of the artificial neural network (ANN) model are used in this paper [20-22].

1.3. The Time Delay in Semiactive Suspension Systems. According to the results of simulation in many studies, semiactive control offers satisfactory performance, but its performance decreases greatly in practical operation due to the existence of a time delay during signal collection, signal transmission, controller logic calculation, and damper reaction, which leads to a difference between the output force and the ideal needed force [23]. It is well known that time delays cannot be avoided and exist objectively in the control system. It is necessary to research the time delay problem and to analyze the effect of the time delay on the dynamical performance of semiactive control systems.

Time delay in the semiactive control system with MR dampers mainly refers to the response time delay of the MR damper itself and the other time delay of the system. The performance of the semiactive control system will be affected by the time delay existing in signal measuring, actuator acting, signal transmitting, and controller calculating. Time delay generated by the MR damper mainly includes response time of MR fluid, response time of excitation coil, structure time delay, and so on. It is necessary to analyze the effect of time delay in the semiactive control system on the ride index of high-speed railway vehicles.

Many researches focus on the effect of time delay in the control system with MR dampers, including the measurement of time delay, effect of different kinds of time delay on performance of the system, and time delay feedback control. Yanik and Aldemir discovered that the time delay of the semiactive control system is $0 \sim 20 \mathrm{~ms}$ [24]. Huang et al. thought that the integral time constant brings time delay into the semiactive control system, and the value is about $30 \mathrm{~ms}$ [25]. Eslaminasab and Golnaraghi measured that response time delay of the MR damper is about $10 \mathrm{~ms}$, but response time delay of the solenoid-type damper is about in the range of $12.5 \sim 16.5 \mathrm{~ms}[26,27]$. Cha et al. believed that a MR damper of $200 \mathrm{kN}$ capacity needs $18 \mathrm{~ms}$ to reach the required control current and $550 \mathrm{~ms}$ to reach the required damping force [28].

Time delay of ordinary dampers is much larger than that of MR dampers. Spelta et al. discovered that when conducting semiactive control to rear suspension system of the motorcycle by using a hydraulic valve damper, the time delay of current signal is less than $10 \mathrm{~ms}$, and actuator time delay is not more than $20 \mathrm{~ms}$ [29]. Simoneschi et al. observed that the control system is not able to apply a control force of any amplitude to the system due to some delays related to the real characteristics of the instrumentation, and the sampling time delay is about $100 \mathrm{~ms}$ and the classical time delay is $50 \mathrm{~ms}$ [30]. Li et al. discovered that time delay of the ordinary damper is about $200 \mathrm{~ms}$ when the cloud-aided semiactive suspension is applied [31]. Sarami found that response time delay of the solenoid-type damper is about in the range of $20 \sim 35 \mathrm{~ms}$, and the largest time delay of the completely semiactive control system is $40 \mathrm{~ms}$ in studying semiactive control of the whole vehicle suspension system [32].

1.4. The Novelty and Organization of This Paper. In this paper, a whole railway vehicle model with 50 -DOF is built and simulated based on VI-Rail and SIMULINK software. Two MR dampers are used in the secondary suspension of each bogie to replace the conditional lateral passive dampers. Several semiactive control strategies are conducted and their performance is checked through dynamic simulation. The 
different effects of two time delays in the semiactive control system are compared, and a new analysis method based on $3 \mathrm{D}$ curve surface figures is proposed to evaluate the effect of the time delay on the riding comfort of high-speed railway vehicles.

This paper is organized as follows: In Section 2, a 50DOF vehicle model based on China's high-speed railway vehicles is built using VI-Rail and is validated and evaluated using multiple dynamic performance indices, such as the nonlinear critical speed, ride index, derailment index, and wheel unloading rate. Track irregularity excitation is also considered, and the railway vehicle is reorganized using cosimulations of VI-Rail and SIMULINK. The evaluation method of ride comfort of railway vehicles is described, and dynamic simulation conditions, track irregularities, and simulation time and steps are introduced. The performance of several control strategies and passive suspension on the ride index of railway vehicles are also compared in Section 2 . In Section 3, two semiactive control strategies and a mixed structure of the two are introduced, and the three controllers are presented in the SIMULINK environment. After testing a self-designed MR damper on the test rig, the forward model and the inverse model of the MR dampers are developed. In Section 4, the complete semiactive control suspension of the railway vehicles is developed, and the necessary validation of the model is conducted. The context of all sections in this paper is introduced here. In Section 5, two kinds of time delay in the semiactive control system are described, and the analysis method of effect of time delays on the ride index is proposed. Then, the effect of two kinds of time delay on the ride index of high-speed railway vehicles at running speed from 250 to $350 \mathrm{~km} / \mathrm{h}$ is simulated and analysed in Section 3. In Section 6, the conclusion of this paper is given.

\section{High-Speed Railway Vehicle Model}

2.1. Modelling. A high-speed railway vehicle model is built using the multibody dynamic software VI-Rail. As shown in Figure 1, the bogie model includes the traction motor and the drive system. The nonlinear characteristics of the spring and damper of the primary and secondary suspension are considered in the model, and nonlinear components such as rubber bushes, stop catches, and the traction motor are built. A whole railway vehicle model consists of two bogies and one car body, as shown in Figure 2. The railway vehicle model has 50 DOF, which includes 6 DOF (surge, heave, sway, yaw, pitch, and roll motions) for each car body, bogie frame, and wheelset, and 1 DOF (pitch) for each axle box rotating arm.

The axle box rotating arm consists of an axle box and a rotating arm, which is located between the wheelset and the bogie frame and rotates around the wheelsets within a small range. The axle box rotating arm is connected to the bogie frame using a bushing element, which is defined by three force and torque values $\left(F_{x}, F_{y}, F_{z}, T_{x}, T_{y}\right.$, and $\left.T_{z}\right)$.

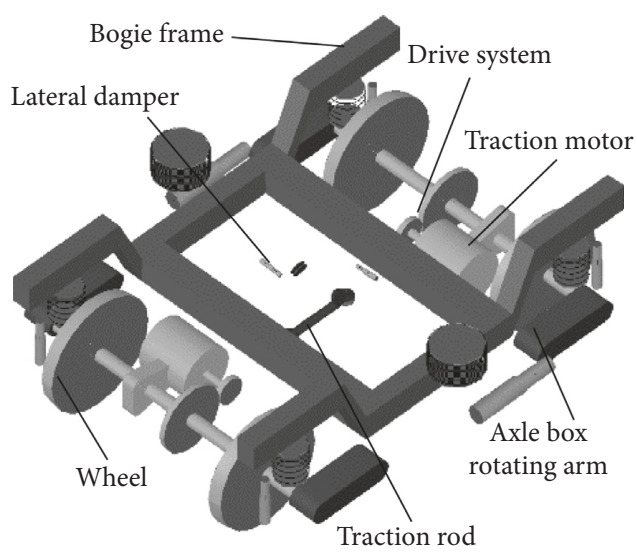

Figure 1: Railway vehicle bogie model.

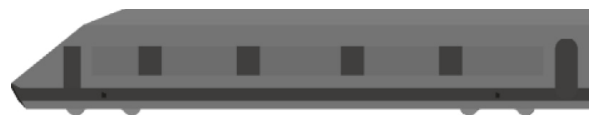

Figure 2: Model of a high-speed railway vehicle.

$$
\begin{aligned}
{\left[\begin{array}{l}
F_{x} \\
F_{y} \\
F_{z} \\
T_{x} \\
T_{y} \\
T_{z}
\end{array}\right]=} & -\left[\begin{array}{cccccc}
k_{11} & 0 & 0 & 0 & 0 & 0 \\
0 & k_{22} & 0 & 0 & 0 & 0 \\
0 & 0 & k_{33} & 0 & 0 & 0 \\
0 & 0 & 0 & k_{44} & 0 & 0 \\
0 & 0 & 0 & 0 & k_{55} & 0 \\
0 & 0 & 0 & 0 & 0 & k_{66}
\end{array}\right]\left[\begin{array}{c}
x \\
y \\
z \\
\varphi \\
\phi \\
\theta
\end{array}\right] \\
& -\left[\begin{array}{cccccc}
c_{11} & 0 & 0 & 0 & 0 & 0 \\
0 & c_{22} & 0 & 0 & 0 & 0 \\
0 & 0 & c_{33} & 0 & 0 & 0 \\
0 & 0 & 0 & c_{44} & 0 & 0 \\
0 & 0 & 0 & 0 & c_{55} & 0 \\
0 & 0 & 0 & 0 & 0 & c_{66}
\end{array}\right]\left[\begin{array}{c}
\dot{x} \\
\dot{y} \\
\dot{z} \\
\dot{\varphi} \\
\dot{\phi} \\
\dot{\theta}
\end{array}\right]+\left[\begin{array}{l}
F_{1} \\
F_{2} \\
F_{3} \\
T_{1} \\
T_{2} \\
T_{3}
\end{array}\right],
\end{aligned}
$$

where $F$ and $T$ are the force and torque of the bushing, respectively, $x, y, z, \phi, \varphi$, and $\theta$ mean the relative displacement and relative angle along or around the $X$-, $Y$-, and $Z$-axes, respectively, $\dot{x}, \dot{y}, \dot{z}, \dot{\phi}$, $\dot{\varphi}$, and $\dot{\theta}$ are the relative velocity and relative angle velocity, respectively, $k$ and $c$ represent the stiffness coefficient and damping coefficient, respectively, $F_{1}, F_{2}$, and $F_{3}$ represent the initial force of the bushing along the $X$-, $Y$-, and $Z$-axes, respectively, and $T_{1}, T_{2}$, and $T_{3}$ are the initial torques of the bushing around the $X$-, $Y$-, and $Z$-axes, respectively.

The LMA wheel profile and HN60 rail head profile are chosen for the vehicle model proposed in the paper. In the software VI-Rail, the creep force between the wheel and the rail is calculated based on the theories of Johnson and Kalker, and several relationship equations of the creep rate and creep force are available, such as the Hertz contact 
theory, the Kalker table method from CONTACT, Kalker's FASTSIM and its modified version, the Polach approximate function calculation method, and the Johnson-Vermeulen approximation equation, in which spinning is considered. Three wheel-rail contact models are provided in VI-Rail, namely, a linear wheel-rail model, the calculation table of a nonlinear wheel-rail model, and a common nonlinear wheel-rail model. In this paper, the common nonlinear wheel-rail model is used to ensure calculation accuracy. German railway spectra of low irregularity are used for excitation of the vehicle model, and both straight and curved track lines are considered.

2.2. Evaluation of Ride Comfort of Railway Vehicles. The ride index of railway vehicles can be calculated according to a standard of China railway GB 5599-85 [33], and the formula is shown as

$$
W=7.08 \sqrt[10]{\frac{A^{3}}{f} F(f)},
$$

where $w$ is the ride index of railway vehicles, $A$ is the vibration acceleration of the car body, in which the unit is $g, f$ is the vibration frequency, in which the unit is $\mathrm{Hz}$, and $F(f)$ is the correction coefficient of vibration frequency. The formula of lateral vibration is shown as

$$
F(f)= \begin{cases}0.8 f^{2}, & f=0.5 \sim 5.4 \mathrm{~Hz}, \\ \frac{650}{f^{2}}, & f=5.4 \sim 26 \mathrm{~Hz}, \\ 1, & f>26 \mathrm{~Hz} .\end{cases}
$$

The ride comfort of a passenger railway vehicle is evaluated by Table 1 .

2.3. Simulation Condition Setting. A straight track line is used to complete dynamic simulation of ride comfort, and the track irregularity is German railway spectra of low irregularity. The total simulation time is $90 \mathrm{~s}$, and the time is separated to five sections of $18 \mathrm{~s}$. With the five sections' data, the ride index is calculated, respectively, and the mean value of the ride index is obtained. The time step of simulation is $0.005 \mathrm{~s}$.

Random track irregularity is calculated by using the power spectral density (PSD) method as the excitation of railway vehicles. The track geometric irregularity includes four kinds: vertical irregularity, alignment irregularity, cross-level irregularity, and gauge irregularity, and their expressions are as follows:

Vertical irregularity:

$$
S_{\mathrm{v}}(\Omega)=\frac{A_{\mathrm{v}} \Omega_{\mathrm{c}}^{2}}{\left(\Omega^{2}+\Omega_{\mathrm{r}}^{2}\right)\left(\Omega^{2}+\Omega_{\mathrm{c}}^{2}\right)} \mathrm{m}^{2} / \mathrm{rad} \cdot \mathrm{m}^{-1} .
$$

Alignment irregularity:

$$
S_{\mathrm{a}}(\Omega)=\frac{A_{\mathrm{a}} \Omega_{\mathrm{c}}^{2}}{\left(\Omega^{2}+\Omega_{\mathrm{r}}^{2}\right)\left(\Omega^{2}+\Omega_{\mathrm{c}}^{2}\right)} \mathrm{m}^{2} / \mathrm{rad} \cdot \mathrm{m}^{-1} .
$$

TABLE 1: Grades of running stability for the passenger car.

\begin{tabular}{lcc}
\hline Ride comfort levels & Evaluation results & Ride index $W$ \\
\hline First & Excellent & $<2.5$ \\
Second & Good & $2.5 \sim 2.75$ \\
Third & Pass & $2.75 \sim 3.0$ \\
\hline
\end{tabular}

Cross-level irregularity:

$$
S_{\mathrm{c}}(\Omega)=\frac{A_{\mathrm{v}} / b^{2} \cdot \Omega^{2} \cdot \Omega_{\mathrm{c}}^{2}}{\left(\Omega^{2}+\Omega_{\mathrm{r}}^{2}\right)\left(\Omega^{2}+\Omega_{\mathrm{c}}^{2}\right)\left(\Omega^{2}+\Omega_{\mathrm{s}}^{2}\right)} \mathrm{m}^{2} / \mathrm{rad} \cdot \mathrm{m}^{-1} .
$$

Gauge irregularity:

$$
S_{\mathrm{g}}(\Omega)=\frac{A_{\mathrm{g}} \Omega^{2} \Omega_{\mathrm{c}}^{2}}{\left(\Omega^{2}+\Omega_{\mathrm{r}}^{2}\right)\left(\Omega^{2}+\Omega_{\mathrm{c}}^{2}\right)\left(\Omega^{2}+\Omega_{\mathrm{s}}^{2}\right)} \mathrm{m}^{2} / \mathrm{rad} \cdot \mathrm{m}^{-1} .
$$

where $S(\Omega)$ is the power spectral density of track irregularity; $\Omega$ is the spatial wave number, and when the wave length of irregularity is $L$ and spatial frequency $F=1 / L$, then $\Omega=2 \pi F ; A_{\mathrm{v}}$ and $A_{\mathrm{a}}$ are the roughness constants; $A_{\mathrm{g}}$ is the reference coefficient when the gauge irregularity is between $-3 \mathrm{~mm}$ and $3 \mathrm{~mm} ; \Omega_{\mathrm{c}}$ and $\Omega_{\mathrm{s}}$ are truncated wave numbers; and $b$ is half of the wheel rolling circle distance, and $b=$ $0.7465 \mathrm{~m}$ in this paper.

According to German railway spectra of low irregularity, the values of aforementioned parameters are chosen as

$$
\begin{aligned}
& \Omega_{\mathrm{c}}=0.8246 \mathrm{rad} \cdot \mathrm{m}^{-1}, \\
& \Omega_{\mathrm{r}}=0.0206 \mathrm{rad} \cdot \mathrm{m}^{-1}, \\
& \Omega_{\mathrm{s}}=0.438 \mathrm{rad} \cdot \mathrm{m}^{-1}, \\
& A_{\mathrm{a}}=2.119 \times 10^{-7} \mathrm{~m} \cdot \mathrm{rad}, \\
& A_{\mathrm{v}}=4.032 \times 10^{-7} \mathrm{~m} \cdot \mathrm{rad}, \\
& A_{\mathrm{g}}=0.532 \times 10^{-7} \mathrm{~m} \cdot \mathrm{rad} .
\end{aligned}
$$

The random irregularity in the time domain can be obtained by using numerical simulation methods. The relationship of left and right rail irregularities $y_{1}, y_{2}, z_{1}, z_{2}$ and four kinds of irregularities in the time domain, vertical irregularity $z_{\mathrm{v}}$, alignment irregularity $y_{\mathrm{a}}$, cross-level irregularity $z_{\mathrm{c}}$, and gauge irregularity $y_{\mathrm{g}}$, can be expressed as

$$
\begin{aligned}
& z_{1}=z_{\mathrm{v}}+\frac{1}{2} z_{\mathrm{c}}, \\
& z_{1}=z_{\mathrm{v}}-\frac{1}{2} z_{\mathrm{c}}, \\
& y_{1}=y_{1}+\frac{y_{\mathrm{g}}+g}{2}, \\
& y_{2}=y_{1}-\frac{y_{\mathrm{g}}+g}{2},
\end{aligned}
$$

where $g$ is the gauge of the track, $1.435 \mathrm{~m}$ is chosen for China railway lines. The vertical and lateral irregularities of left and right rail in the time domain are shown in Figure 3. 


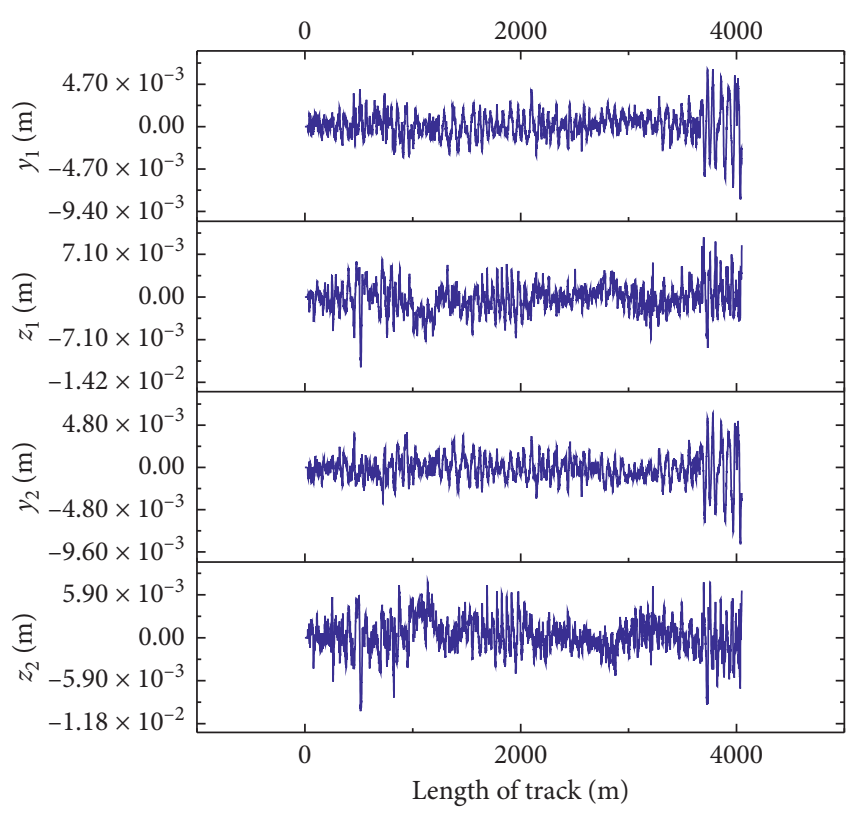

Figure 3: Irregularity curves of German low disturbance line.

2.4. Vehicle Model Validation. To ensure that the vehicle model proposed in this paper meets the requirements, dynamic simulations are conducted, and the lateral stability, ride comfort, and running safety are analysed. In these simulations, the nonlinear critical speed is the evaluation index of lateral stability, the Sperling ride index is the evaluation index of ride comfort, and the derailment index and wheel load unloading rate are the evaluation indices of running safety. The dynamic simulations and calculation methods of the indices are provided in reference [34]. The nonlinear critical speed of the proposed vehicle model is calculated using the method of vehicle speed reduction, and Figure 4 shows that the nonlinear critical speed is as high as $588 \mathrm{~km} / \mathrm{h}$. Therefore, the vehicle model is acceptable in terms of lateral stability.

The vehicle model was simulated as running on a straight track with German railway spectra of low irregularity at $300 \mathrm{~km} / \mathrm{h}$, and the resulting car body lateral acceleration is shown in Figure 5. According to the ride index calculation method [33], the ride index result is 1.881, which is acceptable for the running conditions.

To examine the running safety of the vehicle model on curved lines, a section of special curved lines is designed. The first section of curved lines is a straight line of which the length is $950 \mathrm{~m}$, which is followed by a $200 \mathrm{~m}$ transition curve with a radius varying from infinity to $7000 \mathrm{~m}$. The second section is a curved line with a radius of $7000 \mathrm{~m}$, a length of $1440 \mathrm{~m}$, and a super elevation of $150 \mathrm{~mm}$. The third section includes a transition curve with a length of $260 \mathrm{~m}$ (straight-line length of $1110 \mathrm{~m}$ ). The running speed of the vehicle model is $300 \mathrm{~km} / \mathrm{h}$. Figure 6 shows the derailment index and wheel unloading rate results. The maximum derailment index is 0.126 , and the maximum unloading rate is 0.412 . The results indicate that the running safety of the vehicle model is acceptable.

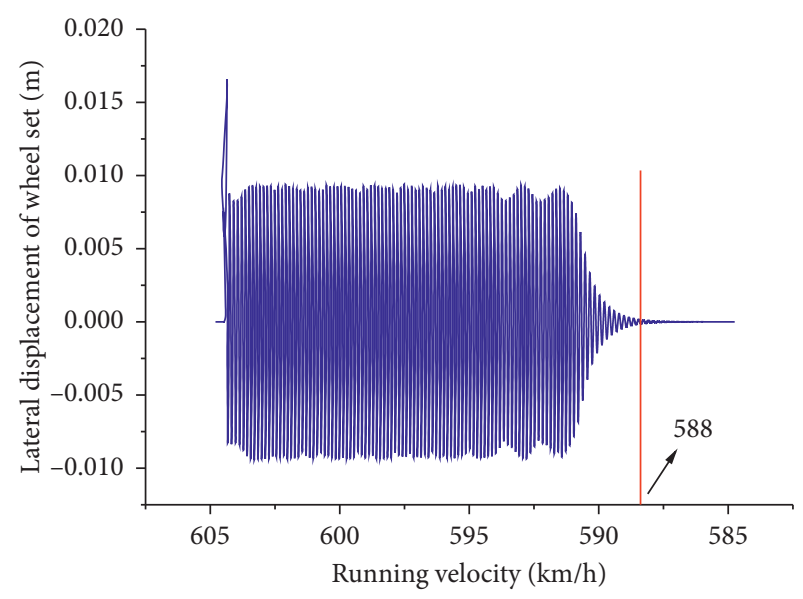

FIGURE 4: Nonlinear critical speed of the proposed vehicle model.

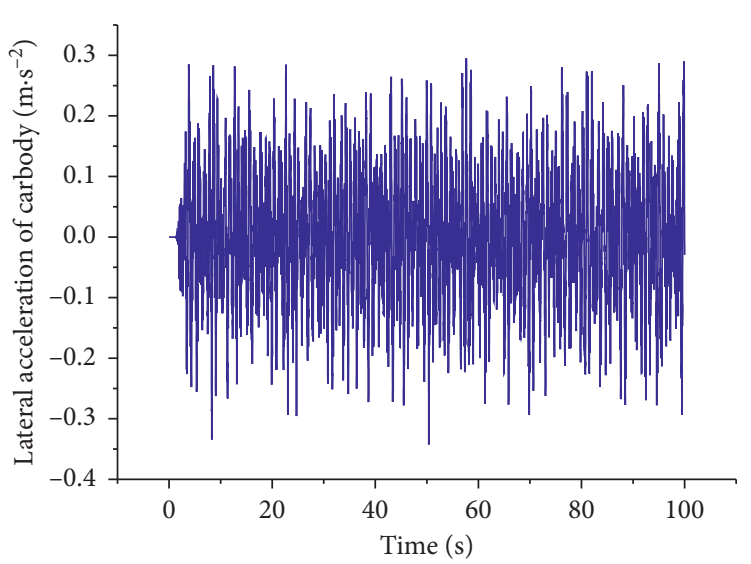

Figure 5: Car body lateral acceleration in the time domain.

\section{Semiactive Control Strategies and MR Damper Models}

\subsection{Semiactive Control Strategies}

3.1.1. SH Control. Karnopp et al. proposed the SH damping method in 1974; this method connects the car body and a fixed reference to reduce vibration of the car body as much as possible [16]. The $\mathrm{SH}$ damping force is shown as follows:

$$
F_{\text {sky }}=c_{\text {sky }} \dot{x}_{2} \text {. }
$$

However, the car body moving in the real world cannot be connected directly with a fixed reference. Therefore, the SH must be designed in another way, as shown in Figure 7. As a result, the control strategy of the $\mathrm{SH}$ is given in equation (11), which is termed SH control.

$$
F= \begin{cases}-c_{\max }\left(\dot{x}_{2}-\dot{x}_{1}\right), & \dot{x}_{2}\left(\dot{x}_{2}-\dot{x}_{1}\right) \geq 0, \\ -c_{\min }\left(\dot{x}_{2}-\dot{x}_{1}\right), & \dot{x}_{2}\left(\dot{x}_{2}-\dot{x}_{1}\right)<0,\end{cases}
$$

where $c_{\max }$ and $c_{\min }$ are the maximum and minimum damping coefficients of the $\mathrm{SH}$ damper, and the value is $1 \times 10^{5} \mathrm{~N} \cdot \mathrm{s} / \mathrm{m}$ and $100 \mathrm{~N} \cdot \mathrm{s} / \mathrm{m}$, respectively, $\dot{x}_{1}$ and $\dot{x}_{2}$ are the absolute lateral velocities of the bogie frame and the car body 


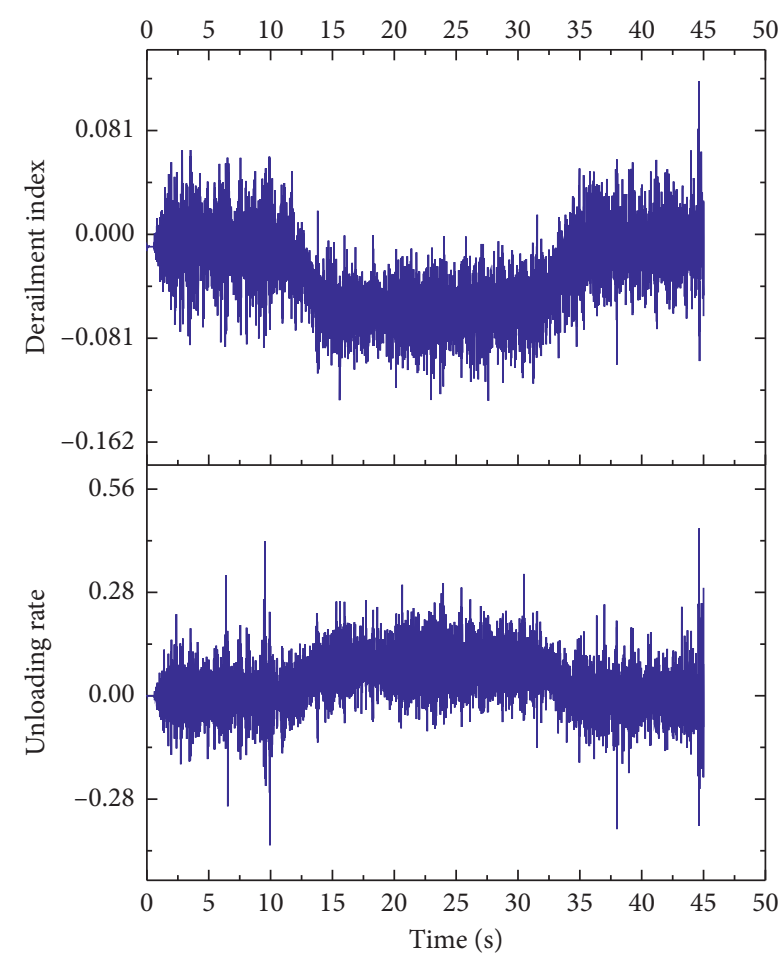

Figure 6: Derailment index and unloading ratio of the vehicle model.

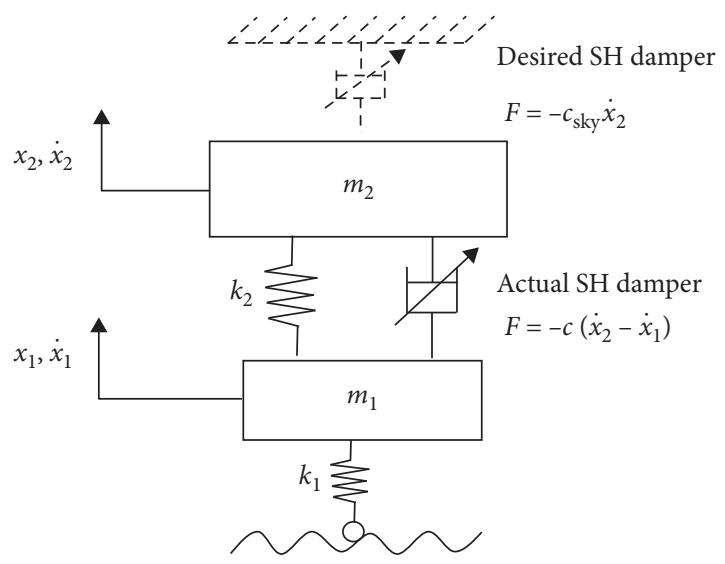

Figure 7: Schematic diagram of desired and actual SH damper system.

in the vehicle model, respectively. In Figure $7, c_{\text {sky }}$ is the desired damping for the $\mathrm{SH}$ damper. To the actual construction of the suspension system, the actual damping is $c$. $m_{2}$ is the quarter car body mass, $m_{1}$ is the unsprung mass (wheelset, brake, axle-box, etc.), and $k_{2}$ and $k_{1}$ are the stiffness of the secondary suspension spring and of primary suspension spring, respectively. The values of these parameters and the way of plotting, Figures 8 and 9 , are shown in Reference [19].

3.1.2. ADD Control. Savaresi et al. proposed the ADD control strategy, in which the switch factor is an acceleration

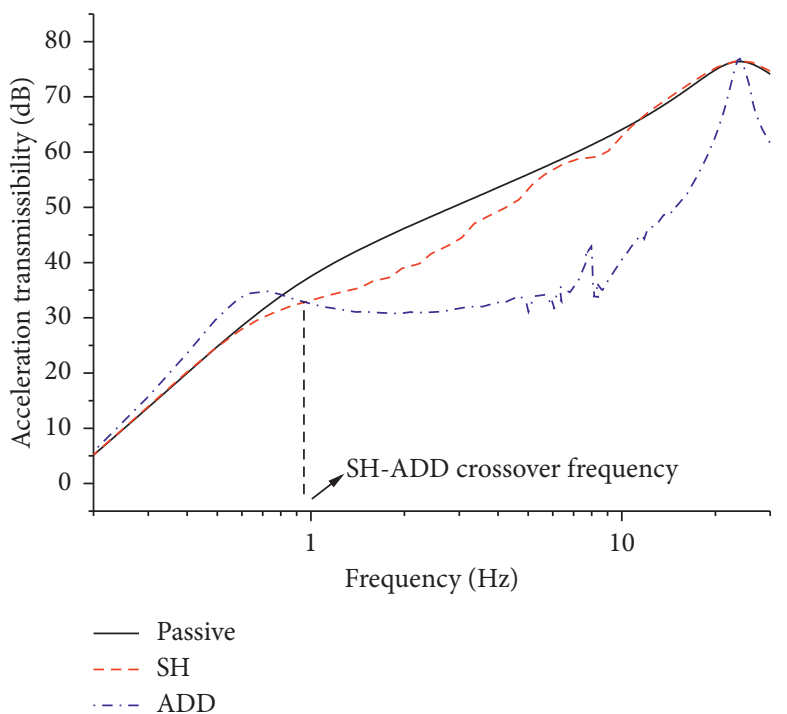

Figure 8: Comparison of transmissibility of several control strategies.

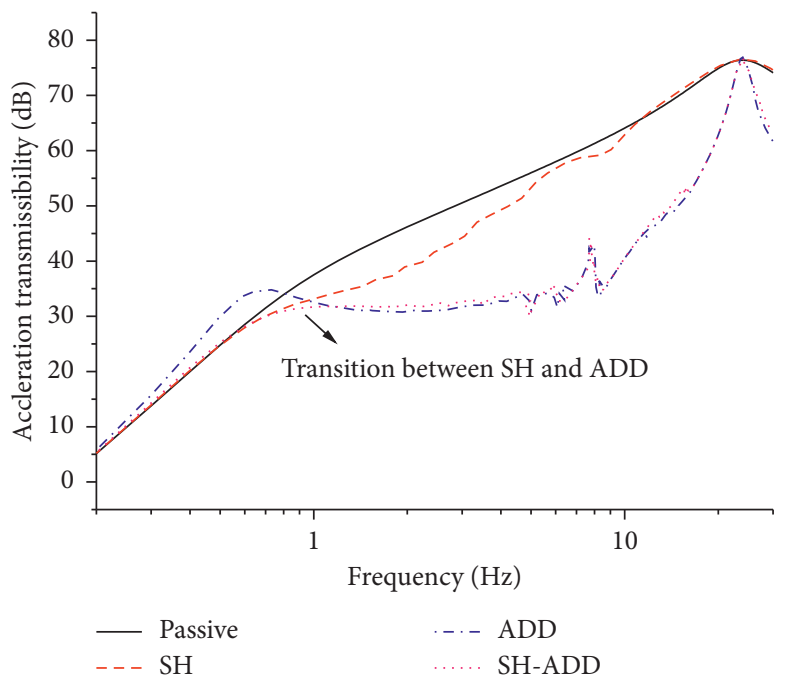

Figure 9: Performance of mixed SH-ADD control in the quarter model.

signal, not the velocity signal used in SH control (the absolute velocity signal is difficult to measure commonly) [19]. The ADD control strategy is shown as follows:

$$
F= \begin{cases}-c_{\max }\left(\dot{x}_{2}-\dot{x}_{1}\right), & \ddot{x}_{2}\left(\dot{x}_{2}-\dot{x}_{1}\right) \geq 0, \\ -c_{\min }\left(\dot{x}_{2}-\dot{x}_{1}\right), & \ddot{x}_{2}\left(\dot{x}_{2}-\dot{x}_{1}\right)<0,\end{cases}
$$

where $\ddot{x}_{2}$ is the acceleration of the car body.

3.1.3. Mixed SH-ADD Control. A previous study compared the performance of $\mathrm{SH}$ and $\mathrm{ADD}$ in the frequency domain using a quarter car model, and a kind of transmissibility rate concerning the excitation amplitude and acceleration of the car body was defined [19]. Figure 8 shows the comparison results between the two control strategies and passive control. 
The performance of SH control is found to be better than that of ADD control in the low-frequency domain and worse in the high-frequency domain. A cross point exists between $\mathrm{SH}$ and $\mathrm{ADD}$, named the crossover frequency. Therefore, both $\mathrm{SH}$ and $\mathrm{ADD}$ have disadvantages in reducing vibration, and neither is the optimal control strategy. As a result, studying a new control strategy that works well in all frequency domains is essential.

Savaresi et al. proposed a mixed SH-ADD control strategy in 2007, for which an expression is shown as follows [19]:

$$
F= \begin{cases}-c_{\max }\left(\dot{x}_{2}-\dot{x}_{1}\right), & {\left[\left(\ddot{x}_{2}^{2}-\alpha^{2} \dot{x}_{2}^{2} \leq 0\right), \dot{x}_{2}\left(\dot{x}_{2}-\dot{x}_{1}\right) \geq 0\right]} \\ & \text { or }\left[\left(\ddot{x}_{2}^{2}-\alpha^{2} \dot{x}_{2}^{2}>0\right), \ddot{x}_{2}\left(\dot{x}_{2}-\dot{x}_{1}\right) \geq 0\right], \\ -c_{\min }\left(\dot{x}_{2}-\dot{x}_{1}\right), & \text { otherwise, }\end{cases}
$$

where $\alpha$ is the conversion coefficient and $\left(\ddot{x}_{2}^{2}-\alpha^{2} \dot{x}_{2}^{2}\right)$ is the conversion condition. When $\left(\ddot{x}_{2}^{2}-\alpha^{2} \dot{x}_{2}^{2}\right)>0$, ADD control works and SH control does not work. When $\left(\ddot{x}_{2}^{2}-\alpha^{2} \dot{x}_{2}^{2}\right) \leq 0$, $\mathrm{SH}$ control works and ADD control does not work. Hence, the value of the conversion coefficient $\alpha$ is very important. Savaresi and Spelta suggested that the relationship between the conversion coefficient $\alpha$ and the crossover frequency $f_{\text {cross }}$ be defined as

$$
\alpha=2 \pi f_{\text {cross }} .
$$

However, the crossover frequency $f_{\text {cross }}$ is not a fixed value when the train speed varies. According to the analysis results, the empirical equation of the crossover coefficient $\alpha$ is defined as

$$
\alpha=-614 \overline{\ddot{x}}_{2}+55.74,
$$

where $\overline{\ddot{x}}_{2}$ is the root mean square (RMS) of the car body lateral acceleration, of which the initial value is $0 ; 10$ seconds later, the value is the RMS of the last 10 seconds of car body lateral acceleration.

To validate the performance of mixed SH-ADD control, a comparison of several controls in the quarter car model is shown in Figure 9, and $\alpha$ is calculated from equation (15).

We find that mixed SH-ADD control can transition from $\mathrm{SH}$ to ADD smoothly at the crossover frequency point, which indicates that the conversion between SH and ADD defined in Equation (13) is successful. Therefore, mixed SHADD control can perform well in all frequency domains; the validation of its performance in the high-speed railway vehicle model is performed later.

The semiactive control strategies mentioned above can be built as semiactive controllers using SIMULINK software, as shown in Figure 10, for which the input signals are the lateral velocity of the car body, the lateral velocity of the bogie frame, and the lateral acceleration of the car body, and the output signal is the desired controlled damping force.

3.2. Forward Model of MR Dampers. A self-designed MR damper is tested on an MTS 793 test rig when the current values and sine signal excitation amplitude and frequency are

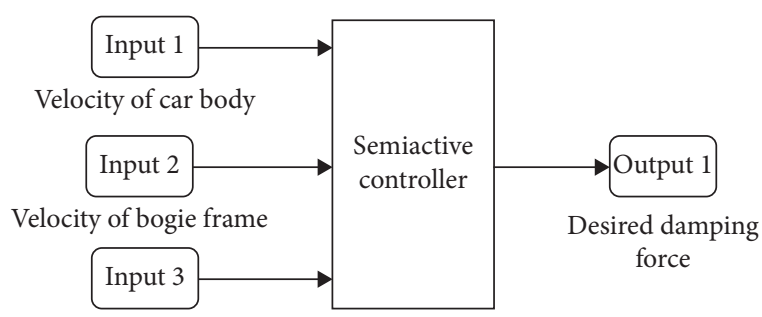

Acceleration of car body

FIgURE 10: Model of semiactive controller in SIMULINK.

changing. The self-designed MR damper has no compensation cavity, and the material of the cylinder body is low-carbon steel, while the material of the piston rod is UN-conducted magnetic material. The coil is twined inside the piston and can be extended outside the piston for current adjustment. The maximum distance of travel is $50 \mathrm{~mm}$, and the maximum damping force is $2500 \mathrm{~N}$ under a maximum current of $2.5 \mathrm{~A}$. Figure 11 shows the test results under a sine signal amplitude of $10 \mathrm{~mm}$ and an excitation frequency of $0.5 \mathrm{~Hz}$.

The Bouc-Wen model of MR dampers was proposed by Bouc and Wen together and is composed of a hysteresis system, spring and damper in parallel connection. The Bouc-Wen model can accurately simulate the hysteresis characteristics of MR dampers; its expression is shown as follows:

$$
F=c_{0} \dot{x}+k_{0}\left(x-x_{0}\right)+\alpha z,
$$

where the hysteresis variable $z$ is defined as

$$
\dot{z}=-\gamma|\dot{x}| z|z|^{n-1}-\beta \dot{x}|z|^{n}+A \dot{x},
$$

where $x$ and $\dot{x}$ are the relative displacement and relative velocity between the two heads of the dampers, respectively, $x_{0}$ is the initial deformation of the spring, of which the stiffness is $k_{0}$, and $A, \beta, \gamma$, and $n$ are the amplitude of the hysteresis loop, the shape of the hysteresis loop, the linearity of the transition section, and the smoothness of the transition section, respectively.

Using a quantizing method and the single parameter adjustment method (SPAM), as the identification methods, the parameters of the Bouc-Wen model are identified. The method is proposed to solve the problem of needing too much prior knowledge in identifying the parameters of the Bouc-Wen model. The detailed information and process of the method are shown in reference [35]. The identification result of the Bouc-Wen model is expressed as

$$
\begin{aligned}
\alpha & =31.58 I+2.21 \times 10^{3}, \\
c_{0} & =7.21 I+5.62, \\
k_{0} & =0.92, \\
\gamma & =1.14 e^{0.026 I}+6.90 e^{2.13 \times 10^{-5} I}, \\
\beta & =2.01 \times 10^{-3}, \\
A & =1.08, \\
n & =0.34 e^{0.95 I}+0.42 e^{0.58 I}, \\
x_{0} & =0.59 .
\end{aligned}
$$




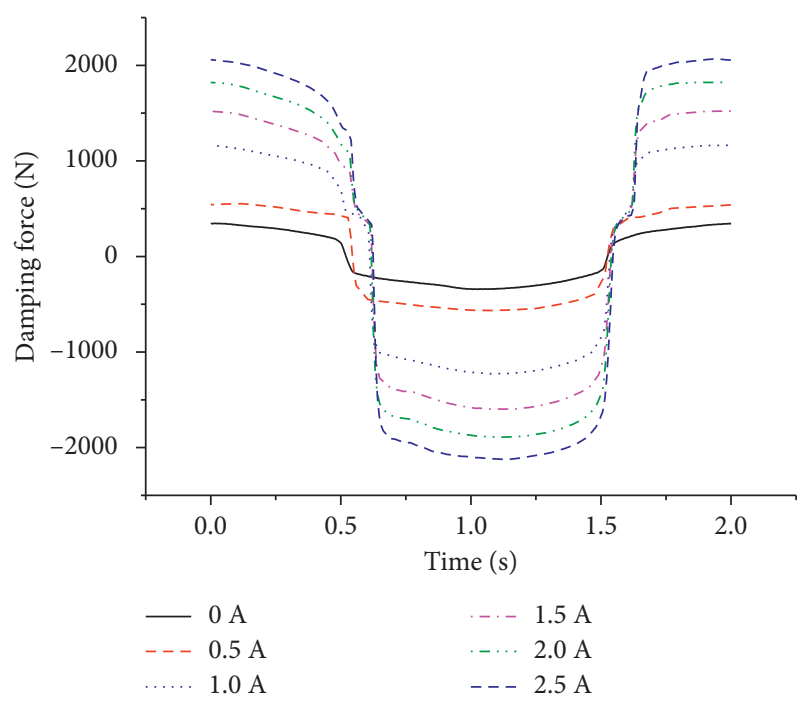

FIgURE 11: Experimental curves of a self-designed MR damper.

A comparison of the simulation results and experimental results is shown in Figure 12 which indicates that the identified model can simulate the actual hysteresis characteristics of MR dampers.

The identified MR damper model can be built as a forward model using SIMULINK software, as shown in Figure 13, for which the input signals are the coil current, relative velocity, and relative displacement of the two heads of the MR dampers, and the output signals are the damping force. The function of the MR damper forward model represents the actual MR dampers in the simulation model.

3.3. Inverse Model of MR Dampers. The forward model of MR dampers is used to simulate the hysteresis characteristics of actual MR dampers, and a kind of inverse model is needed between the semiactive controllers and forward models. The output signals of the semiactive controllers include the desired damping force, and the input signals of the forward models include the coil current command. Therefore, the function of the inverse model of MR dampers is to produce the current command according to the desired damping force, displacement, and velocity signals from the railway vehicle model. The inverse model of MR dampers is built using an ANN method in this paper. The ANN model includes one input layer with four nodes, two hidden layers with four and sixteen nodes, and an output layer with one node.

The input and output signals of the inverse ANN model are expressed as

$$
\begin{aligned}
X_{\text {in }} & =\left[x_{k}, \dot{x}_{k}, F_{k}, I_{k-1}\right], \\
Y_{\text {out }} & =I_{k},
\end{aligned}
$$

where $x_{k}$ is the $k^{\text {th }}$ displacement signal, $\dot{x}_{k}$ is the $k^{\text {th }}$ velocity signal, $F_{k}$ is the $k^{\text {th }}$ damping force, and $I_{k-1}$, and $I_{k}$ are the $k^{\text {th }}$ and $k-1^{\text {th }}$ coil current.

The experimental data of the MR dampers mentioned above are used to train the inverse model, and a comparison of the simulation results and actual data is shown in Figure 14.

The inverse model of MR dampers can be built in SIMULINK, as shown in Figure 15, for which the input signals are the displacement signal, velocity signal, damping force, and preceding current command, and the output signal is the present current value.

\section{Model of the Semiactive Suspension Control System}

The model of semiactive suspension systems of high-speed railway vehicles based on MR dampers includes the railway vehicle model, semiactive controllers, the inverse model of MR dampers, and the forward model of MR dampers, as shown in Figure 16. The desired damping force from a semiactive controller is compared with the actual damping force from the Bouc-Wen model, and the difference between them is set as an additional input to the inverse model to ensure the accuracy of the output actual damping force.

According to the structure shown in Figure 16, the semiactive suspension system model is combined in SIMULINK, as shown in Figure 17. To avoid the current value from the inverse model exceeding the maximum of the MR dampers, a simple adjuster is positioned between them. A memory block is needed after the forward model of the MR dampers to remove algebraic loops commonly existing in the closed loop. The output actual damping force from the forward model of the MR dampers is compared with the desired damping force from the semiactive controllers, as shown in Figure 18. We find that the actual damping force can track the desired force, except the top values, because the maximum damping force of the MR dampers chosen in the test is slightly smaller than the actual force needed.

To compare the performance of several semiactive control strategies and passive suspension when the railway vehicle is running at a high speed, a series of dynamic simulation and analysis of ride comfort are conducted, while the vehicle speed is between $200 \mathrm{~km} / \mathrm{h}$ and $450 \mathrm{~km} / \mathrm{h}$. The influence of several semiactive controls on the lateral ride index of the railway vehicle is shown in Figure 19.

Figure 19 shows that the performance of SH-ADD control is close to $\mathrm{SH}$ control when the running speed of the vehicle is less than $280 \mathrm{~km} / \mathrm{h}$, and that of SH-ADD control is similar with ADD control when speed is higher than $400 \mathrm{~km} /$ h. However, the performance of SH-ADD is significantly better than the other two semiactive controls when vehicle speed is between 280 and $400 \mathrm{~km} / \mathrm{h}$. Thus, SH-ADD control has both merits of SH control and ADD control, which has the best performance.

The aim of building the high-speed railway vehicle model is to investigate the semiactive control performance in suspension systems. However, the single VI-Rail software cannot complete all works required for semiactive suspension simulation, and cosimulation between VI-Rail and SIMULINK is necessary. Hence, the vehicle model in VI-Rail software is transitioned to SIMULINK. The input signals are the controlled damping force located in four lateral dampers in the railway vehicle model, and the output signals are the 


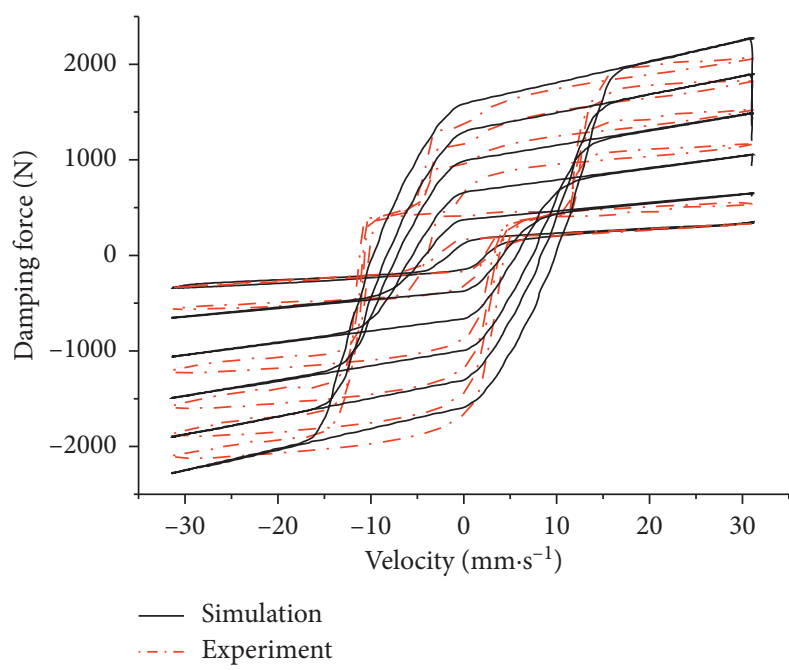

(a)

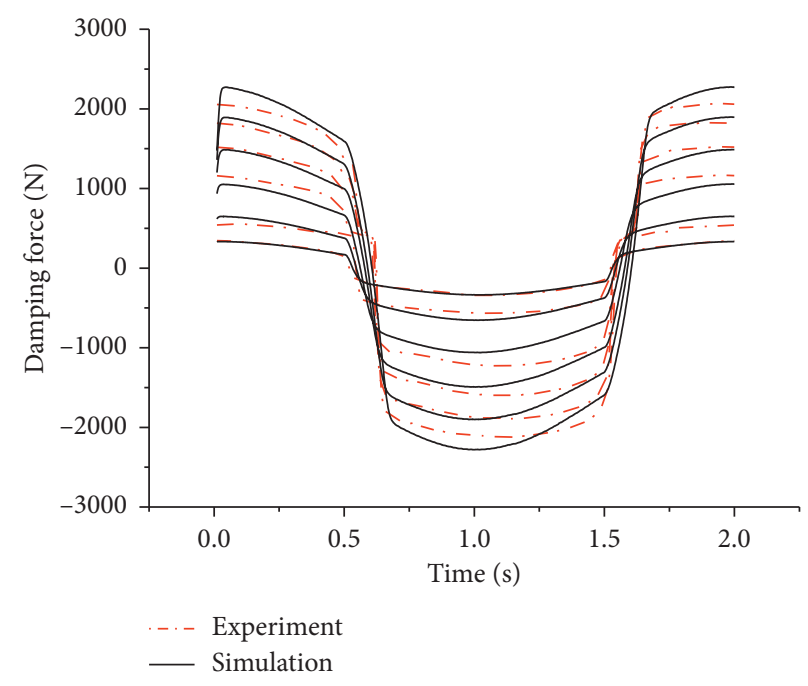

(b)

FIgURE 12: Comparison of simulation results and experimental data at $10 \mathrm{~mm}$ and $0.5 \mathrm{~Hz}$ : (a) velocity vs. damping force; (b) time vs. damping force.

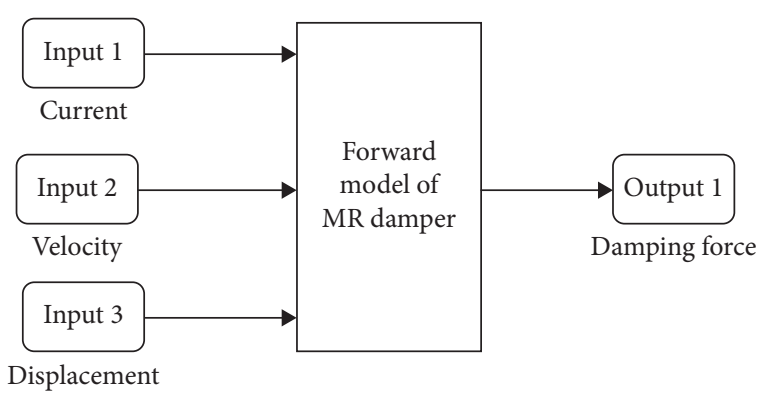

FIGURE 13: Forward model of MR dampers in SIMULINK.

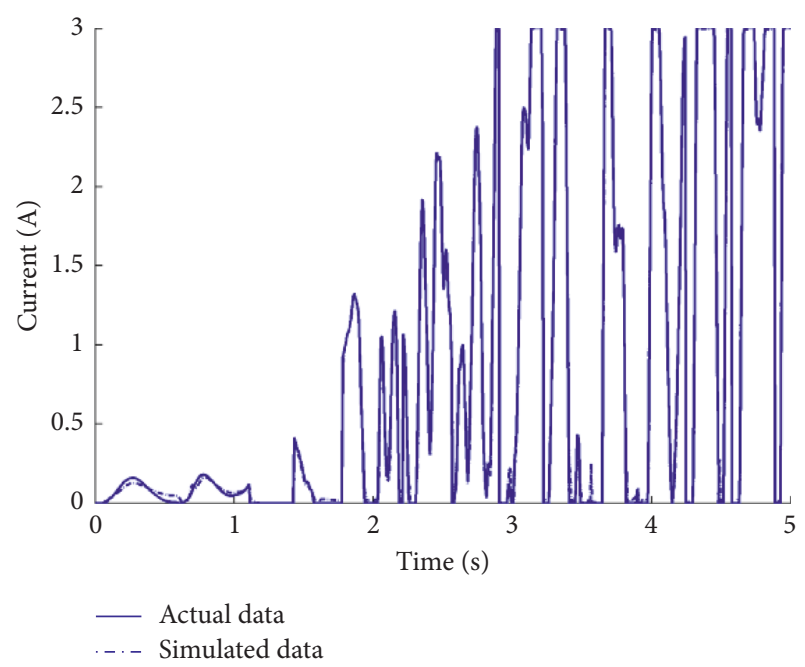

FIGURE 14: Comparison of simulation results and actual data of the inverse MR damper model.

signals needed for semiactive control strategies and some measured signals for evaluating the dynamic performance of the railway vehicle. The cosimulation model in SIMULINK is shown in Figure 20.

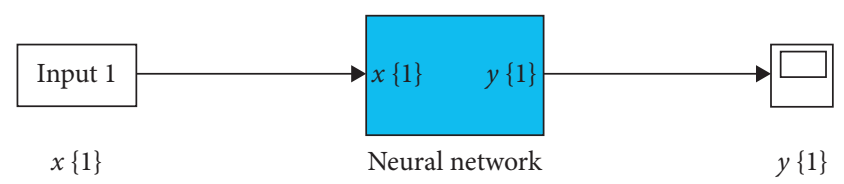

FIgURE 15: The ANN inverse model of the MR damper in SIMULINK.

\section{Effect of Time Delay on Performance of the Semiactive Control System}

5.1. Two Kinds of Time Delay in the Semiactive Control System. According to the different locations and effects, the time delay in the semiactive control system with MR dampers can be classified into two kinds: collection time delay and execution time delay, as shown in Figure 21. Collection time delay refers to the time delay produced in the process of sensor collection signal input into semiactive controller through AC-DC converter. And the execution time delay in this work represents the delay of time in signal transmitting, i.e., the current signal, generating from inverse model, then be transmitted to the forward model, and the damping force is exported finally. The value of time delay for calculation is related to the performance of processors. A high-performance processor is used in this work, so the time delay is only about $0.7 \mathrm{~ms}$, which can be neglected. From above introduction, we can know that execution time delay of the MR damper is less than $10 \mathrm{~ms}$, and time delay of the ordinary damper is no more than $40 \mathrm{~ms}$. Collection time delay of semiactive control is related to the specific hardware such as sensor, filter, and so on; collection time delay is selected as $20 \mathrm{~ms}$ in this work.

The collected signal needs to go through semiactive controller, inverse model, filter, and other links, and then can be putted into forward model, and thus the influence of collection time delay on the system is different from the 


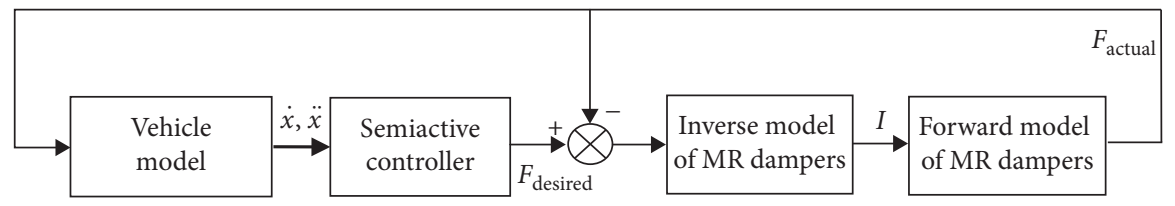

FIGURE 16: Structure of the semiactive suspension system model.

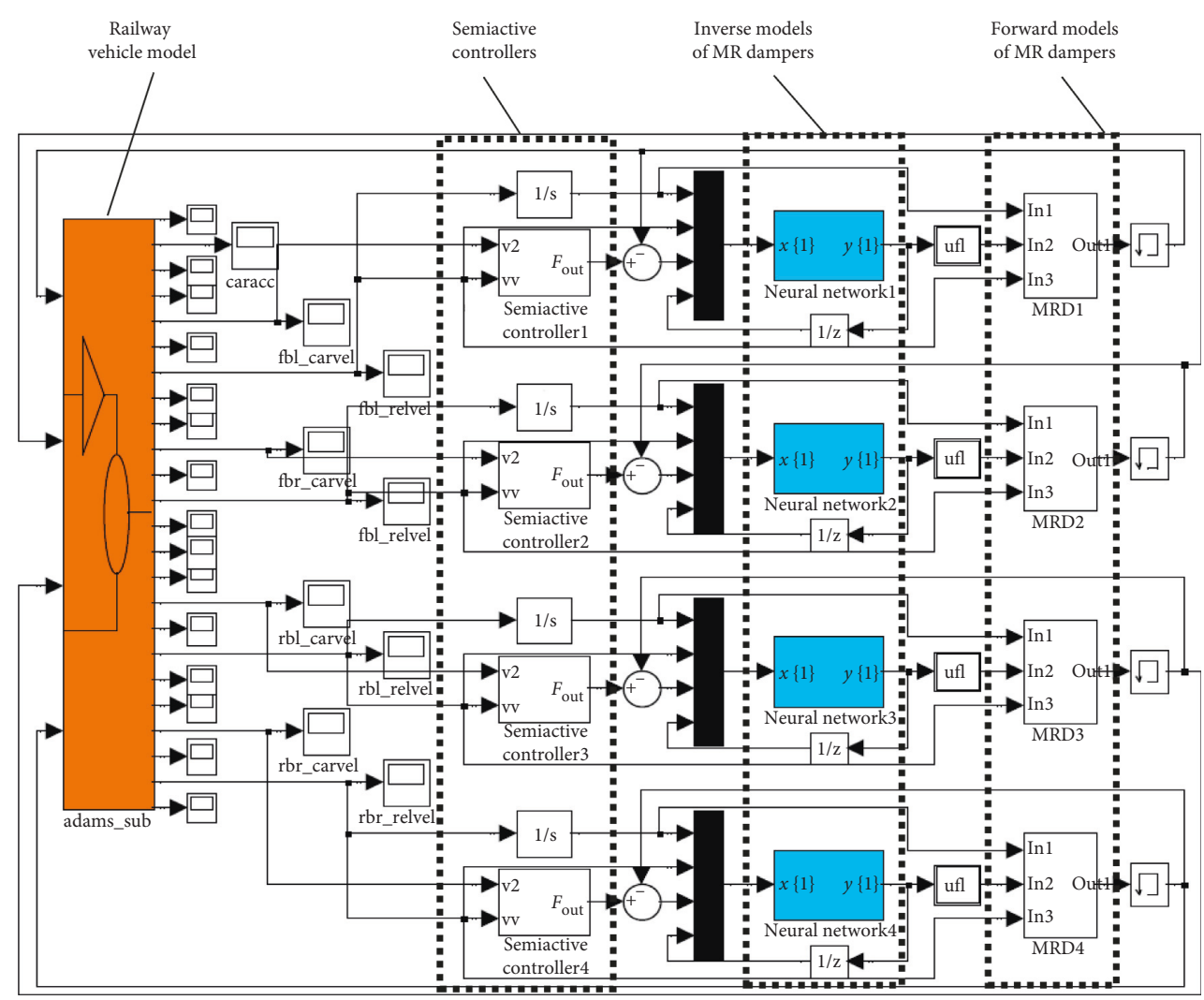

FIGURE 17: Semiactive suspension system model in SIMULINK.

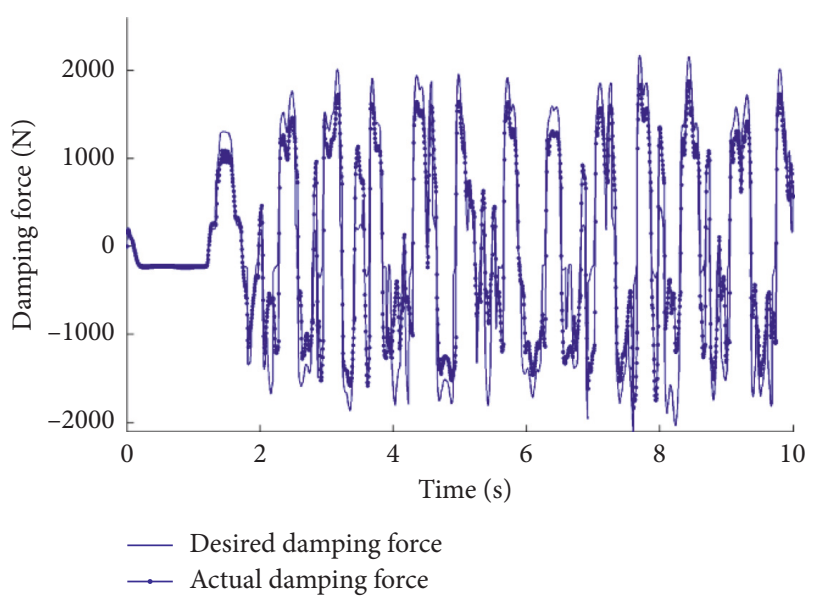

FIgURE 18: Comparison of desired and actual damping force.

execution time delay being in the MR damper. To analyze the effects of collection time delay $\tau_{1}=20 \mathrm{~ms}$ and execution time delay $\tau_{2}=20 \mathrm{~ms}$ on the semiactive control system and

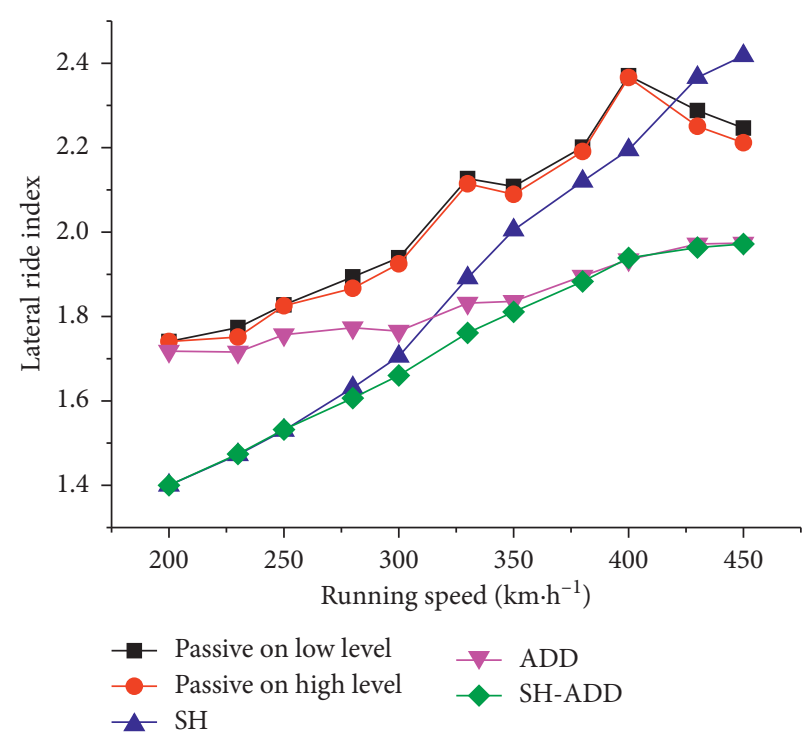

FIGURE 19: Influence of semiactive control on the lateral stability index. 


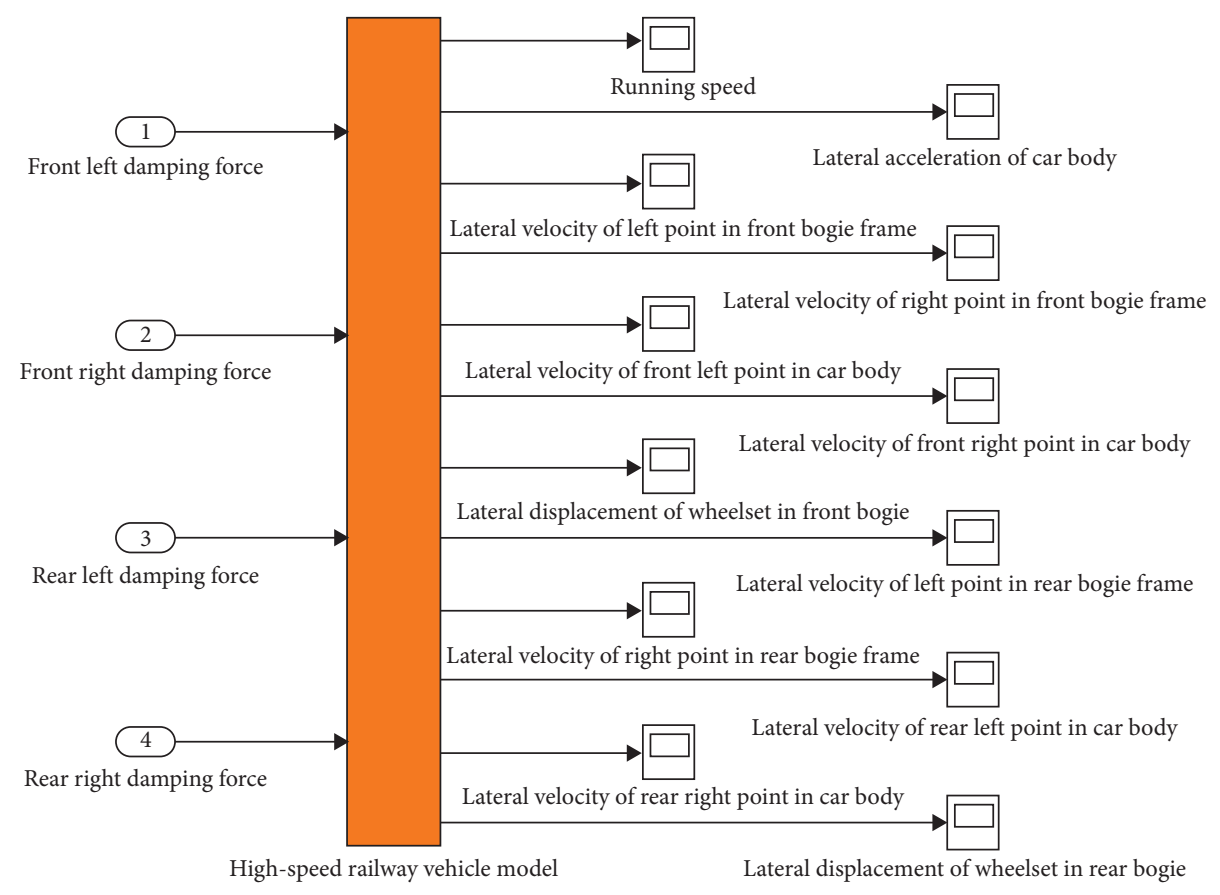

Figure 20: Cosimulation railway vehicle model.

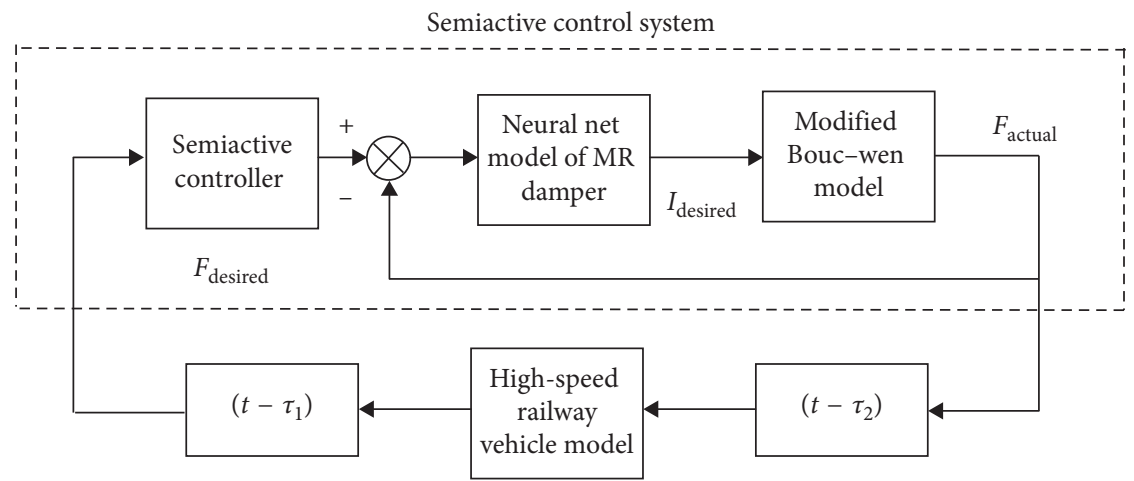

FIgURE 21: Two kinds of time delay of the semiactive control system based on MR dampers.

dynamic response of the model, take $\mathrm{SH}$ control as the example, as shown in Figure 22.

From Figure 22, we can see that different generation mechanism of time delay in semiactive control, then the output current command and control damping force are different under the same value of time delay of $20 \mathrm{~ms}$; as a result, the dynamic responses of the vehicle model are different. But in actual system, both of them coexist, nothing but different value of time delay causes different effects.

\subsection{Analyzing the Method of Two Kinds of Time Delay.} The simulation analysis of collection time delay and execution time delay is conducted by using the cosimulation method of VI-Rail and SIMULINK. Let the value of collection time delay $\tau_{1}$ and execution time delay $\tau_{2}$ in the range of $0 \sim 200 \mathrm{~ms}$ and then conduct simulation, step size of delay is $10 \mathrm{~ms}$ each time. Using German low disturbance rail excitation, high-speed railway vehicle is run at a constant speed of $250 \mathrm{~km} / \mathrm{h}, 300 \mathrm{~km} / \mathrm{h}$, and $350 \mathrm{~km} / \mathrm{h}$, respectively; simulation step size is $0.005 \mathrm{~s}$ and the length of single simulation is $20 \mathrm{~s}$.

According to the simulation results, the matrix form of the lateral ride index of high-speed railway vehicle can be obtained, in which the row vector means the effect of collection time delay and the column vector represents the effect of execution time delay. The ride index matrix $R$ is a $21 \times 21$ square matrix, which can be given by

$$
R=\left[\begin{array}{cccc}
r_{1}^{1} & r_{2}^{1} & \cdots & r_{21}^{1} \\
r_{1}^{2} & r_{2}^{2} & \cdots & r_{21}^{2} \\
\vdots & \vdots & \cdots & \vdots \\
r_{1}^{21} & r_{2}^{21} & \cdots & r_{21}^{21}
\end{array}\right],
$$

where $r_{n}^{m}$ represents collection time delay $\tau_{1}=(m-1) \times$ $10 \mathrm{~ms}$, execution time delay $\tau_{2}=(m-1) \times 10 \mathrm{~ms}$, and $m$ 


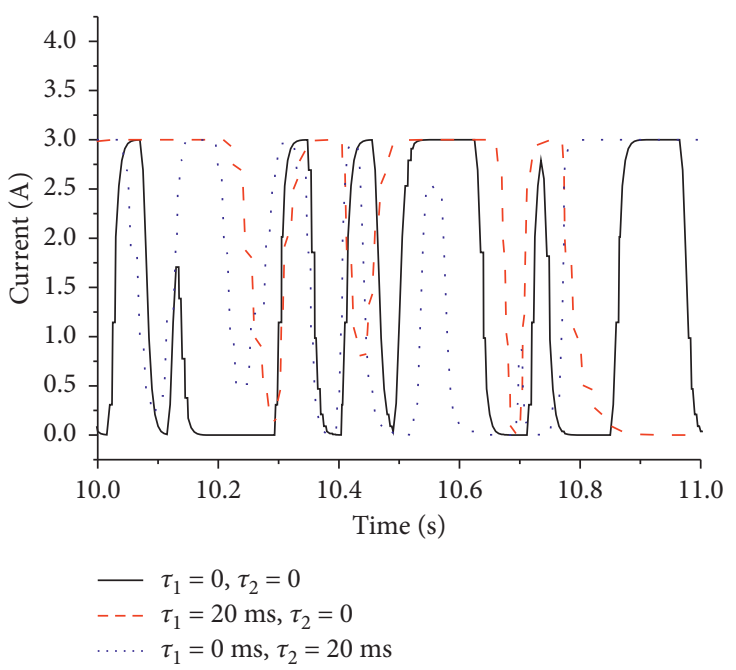

(a)

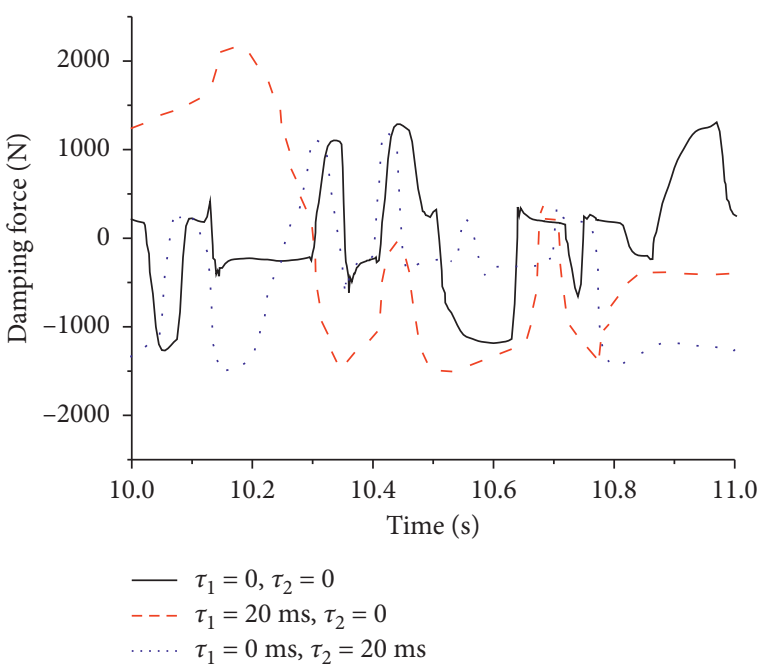

(b)

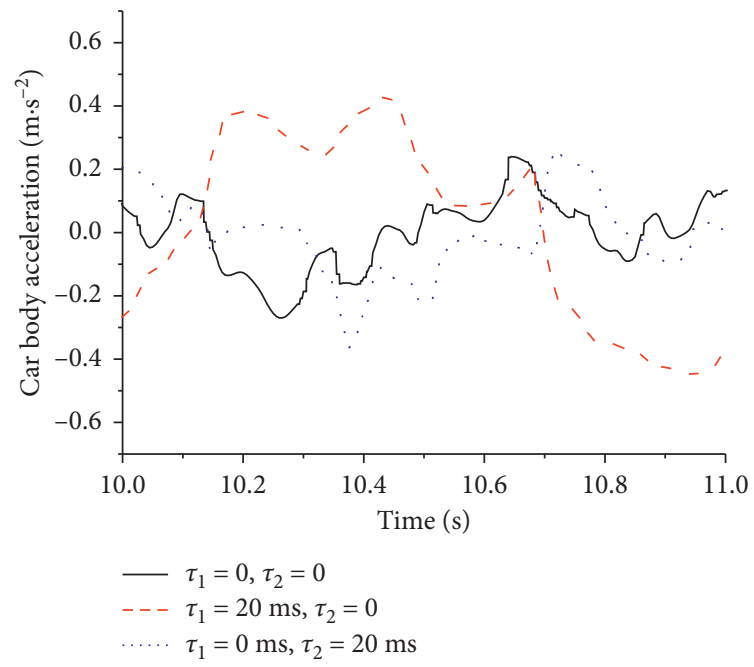

(c)

FIGURE 22: Effects of acquisition time delay and actuation time delay on currents, damping force, and car body acceleration. (a) Current vs. time. (b) Damping force vs. time. (c) Lateral acceleration of the car body.

and $n$ are the column and rows of performance index, respectively.

The matrix $R$ of the lateral ride index can be drawn as $3 \mathrm{D}$ surface, as shown in Figure 23, in which the surface ABC represents the lateral ride index affected by both collection time delay and execution time delay, $X$-axis represents collection time delay $\tau_{1}, Y$-axis represents execution time delay $\tau_{2}$, and $Z$-axis represents the lateral ride index of the vehicle model.

Because the lateral ride index of passive control is not affected by time delay, it can be set as the horizontal plane DEFG which is parallel to the $X-Y$ plane, as shown in Figure 23. The cross curve of surface $\mathrm{ABC}$ and horizontal plane $\mathrm{DEFG}$ is named as curve $\mathrm{DE}$, which is projected on the $X-Y$ plane, thus a ride index contour line of passive control. The contour line is the curve PQ in Figure 23. In this case, the area OPQ enclosed by the time delay boundary curve PQ

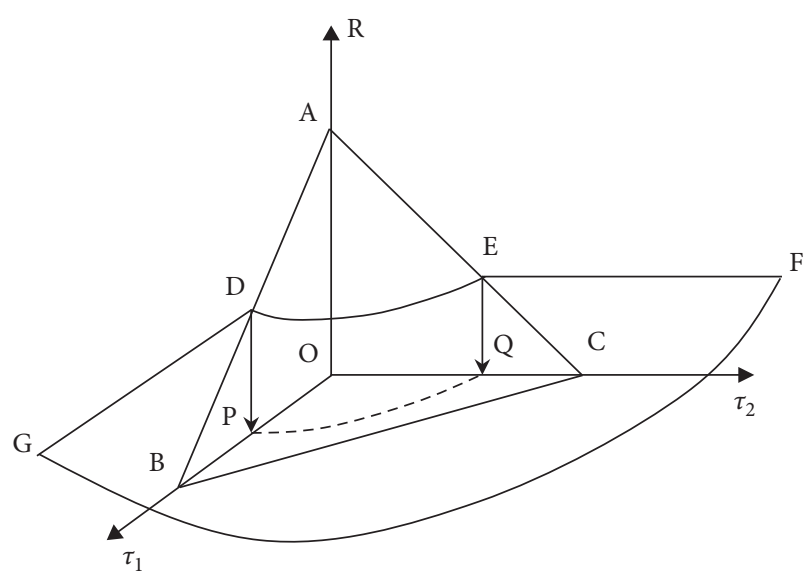

FIgURE 23: Three-dimensional curved face of the lateral ride index matrix $R$. 
and $X$-axis and $Y$-axis is called as the effective region of semiactive control, namely, the shadow area is shown in Figure 24. The area beyond the effective region is called the failure region of this semiactive control. If the coordinate point $\left[\tau_{1}, \tau_{2}\right]$ of collection time delay $\tau_{1}$ and execution time delay $\tau_{2}$ for the semiactive control system is within the effective region, the performance of this semiactive control system with time delay is still good. On the contrary, if the coordinate point $\left[\tau_{1}, \tau_{2}\right]$ is not within the effective region, it indicates that this semiactive control is failure.

5.3. Simulation and Analysis. The influence of collection time delay and execution time delay on semiactive control is studied, respectively, as follows. In Figure 21, the effect of collection time delay $\tau_{1}$ and execution time delay $\tau_{2}$ on the lateral ride index of the high-speed railway vehicle at $250 \mathrm{~km} / \mathrm{h}$ speed under SH control and SH-ADD control is readily observed. The lateral ride index surface of semiactive control crosses with the plane of passive control which forms the time delay boundary curve, as shown in Figure 25.

The area of the effective region enclosed by time delay boundary, collection time delay, and execution time delay represents the ability of against time delay for semiactive control strategy. In the semiactive control effective region, the farther the coordinate point of collection time delay and execution time delay away from the time delay boundary, the better the effect of semiactive control. From Figure 26, it can be seen that when collection time delay is 0 , the permissible maximum execution time delay of the $\mathrm{SH}$ control system is about $160 \mathrm{~ms}$, but the permissible maximum execution time delay of the SH-ADD control system can reach $190 \mathrm{~ms}$ at $250 \mathrm{~km} / \mathrm{h}$ speed. When execution time delay is 0 , the permissible maximum collection time delay of the $\mathrm{SH}$ control system is about $130 \mathrm{~ms}$, but the collection time delay of the SHADD control lower than $150 \mathrm{~ms}$ can be allowed. The effective region area of SH control is much less than that of SH-ADD control, which represents that the time delay robustness of $\mathrm{SH}$ control is weaker than that of SH-ADD control.

Under desired condition without considering time delay, compared with passive control, SH control and SH-ADD control can improve the lateral stability performance of the high-speed railway vehicle and make them increase to $16.72 \%$ and $17.51 \%$, respectively, at $250 \mathrm{~km} / \mathrm{h}$ speed. When time delays of semiactive control with the MR damper are $\tau_{1}=20 \mathrm{~ms}$ and $\tau_{2}=10 \mathrm{~ms}$, SH control and SH-ADD control still can increase lateral stability performance to $15.48 \%$ and $15.58 \%$, respectively.

When time delay reaches to the level of ordinary damper's (considering time delay $\tau_{2}=40 \mathrm{~ms}$, the same below), the effect of two semiactive control strategies decreased, the lateral stability decreased to $14.58 \%$ and $15.38 \%$, respectively. From Figure 26, we can see that when using the MR damper (execution time delay $\tau_{2}=10 \mathrm{~ms}$, the same below), the permissible maximum collection time delay of SH control and SH-ADD control are $130 \mathrm{~ms}$ and $150 \mathrm{~ms}$, respectively, at $250 \mathrm{~km} / \mathrm{h}$ speed. If execution time delay reaches to the level of the ordinary damper, the permissible

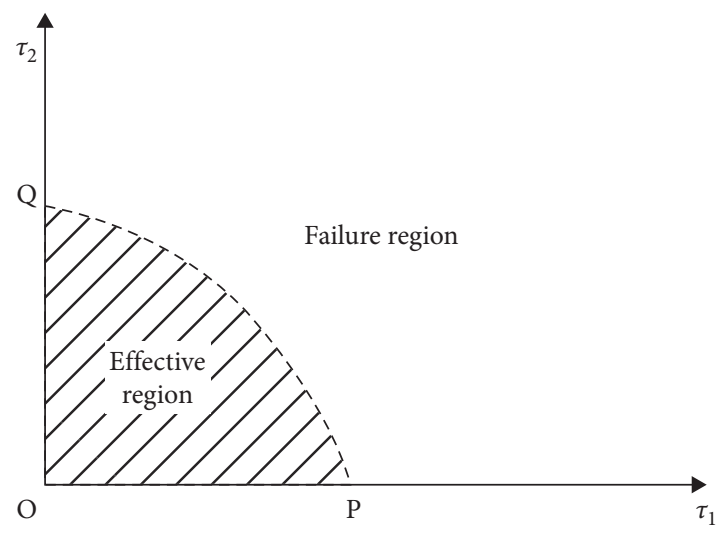

FIgURE 24: Relation of the time delay boundary curve and performance of semiactive control.

maximum collection time delay of $\mathrm{SH}$ control and SH-ADD control are $90 \mathrm{~ms}$ and $110 \mathrm{~ms}$, respectively.

The effect of collection time delay $\tau_{1}$ and execution time delay $\tau_{2}$ on the lateral ride index of the high-speed railway vehicle at $300 \mathrm{~km} / \mathrm{h}$ speed under SH control and SH-ADD control is observed, as shown in Figure 27.

From Figure 27, it can be seen that when collection time delay is 0 , the permissible maximum execution time delay of $\mathrm{SH}$ control is $130 \mathrm{~ms}$, but of SH-ADD control can reach to $160 \mathrm{~ms}$ at $300 \mathrm{~km} / \mathrm{h}$ speed. When execution time delay is 0 , the permissible maximum collection time delay of $\mathrm{SH}$ and SH-ADD control is $90 \mathrm{~ms}$ and $110 \mathrm{~ms}$, respectively. The area of the SH-ADD control effective region is much larger than that of SH control; this shows that against time delay, ability of SH-ADD control is stronger. Comparing with the case at $250 \mathrm{~km} / \mathrm{h}$ speed, as shown in Figure 26, the effective region of semiactive control at a speed of $300 \mathrm{~km} / \mathrm{h}$, as shown in Figure 27 , is obviously reduced; it indicates that with the speed of the high-speed railway vehicle increasing, the effective region of semiactive control is becoming smaller. From Figure 27, we can see that the permissible maximum collection time delay of SH and SH-ADD control at $300 \mathrm{~km} /$ $\mathrm{h}$ speed is $80 \mathrm{~ms}$ and $100 \mathrm{~ms}$, respectively, when using the MR damper. If execution time delay reaches to the level of the ordinary damper, the permissible maximum collection time delay of SH and SH-ADD control is $60 \mathrm{~ms}$ and $80 \mathrm{~ms}$, respectively.

We studied the effect of collection time delay and execution time delay on the lateral ride index at $350 \mathrm{~km} / \mathrm{h}$ speed; the effect of time delay on SH control and SH-ADD control is shown in Figure 28.

At $350 \mathrm{~km} / \mathrm{h}$ speed, compared with passive control, the lateral stability of the high-speed railway vehicle increases to $23.85 \%$ and $25.77 \%$, respectively, under SH control and SHADD control without considering time delay. Furthermore, the lateral stability increases to $16.14 \%$ and $17.28 \%$, respectively, under SH control and SH-ADD control with the MR damper. When the time delay reaches the level of ordinary damper's $(40 \mathrm{~ms})$, the increase extent of two semiactive control strategies in lateral stability drops to $12.83 \%$ and $13.11 \%$, respectively. 


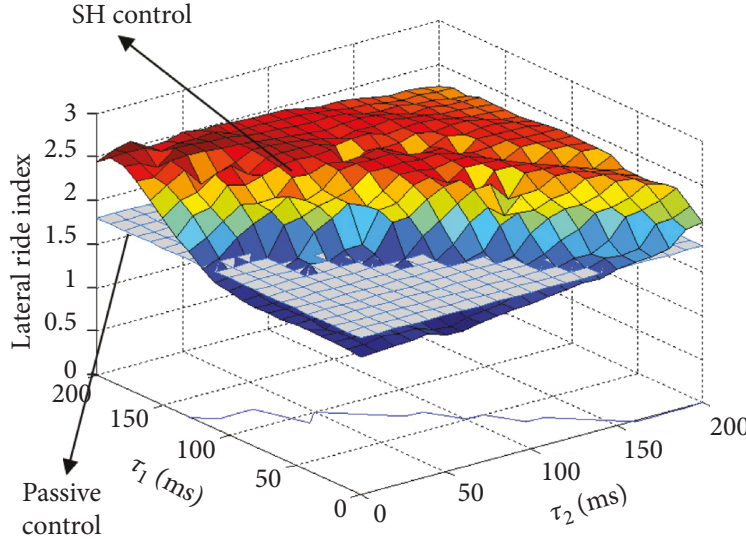

(a)

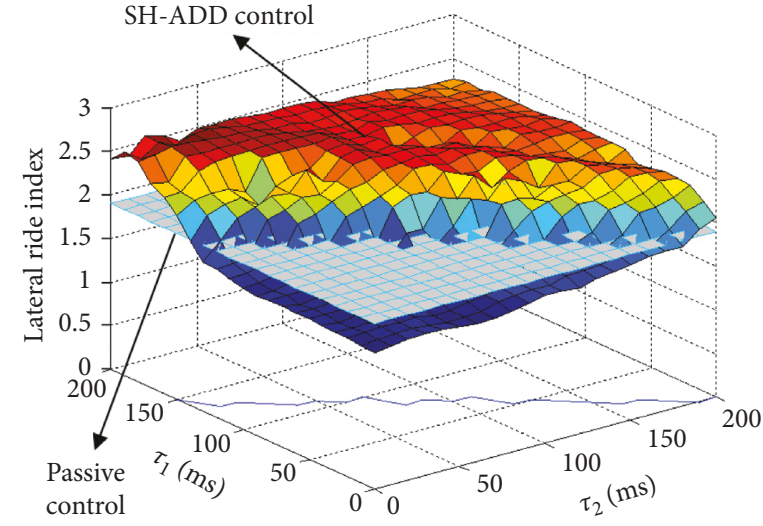

(b)

FIGURE 25: Effects of two kinds of time delay on the lateral ride index with semiactive controls when the velocity is $250 \mathrm{~km} / \mathrm{h}$. (a) $\mathrm{SH}$ control; (b) SH-ADD control.

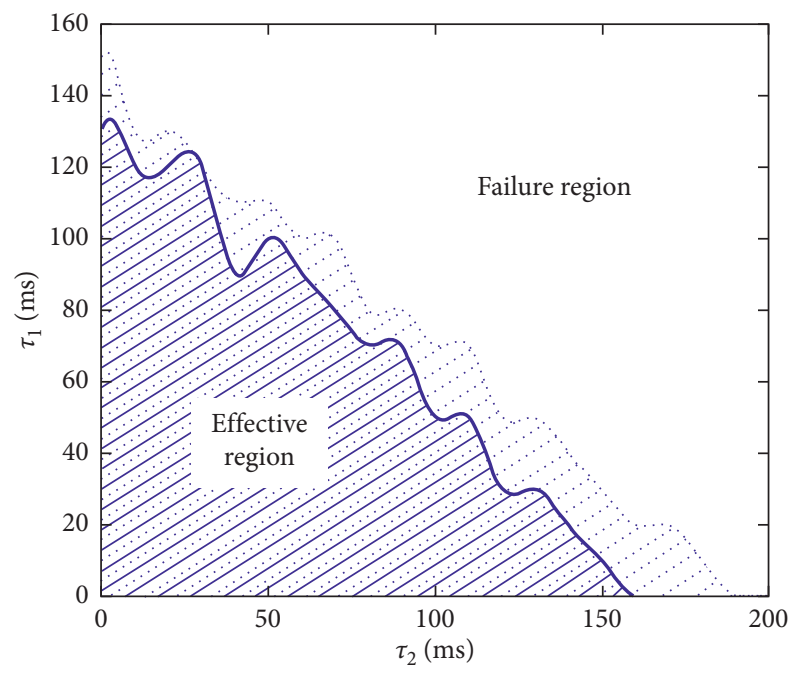

- SH

SH-ADD

Figure 26: Time delay boundary curves of $\mathrm{SH}$ and SH-ADD controls when the velocity is $250 \mathrm{~km} / \mathrm{h}$.

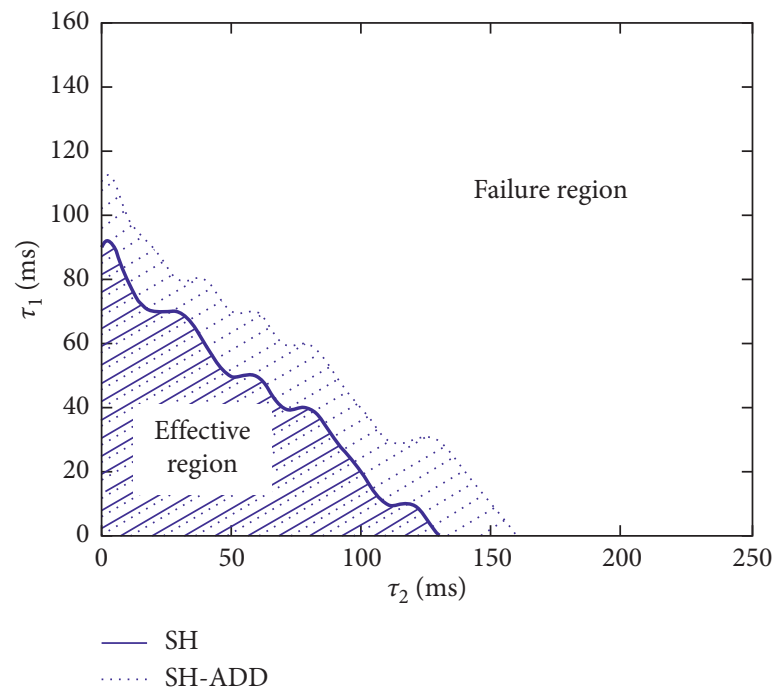

FIGURE 27: Time delay boundary curves of SH and SH-ADD controls when the velocity is $300 \mathrm{~km} / \mathrm{h}$. 


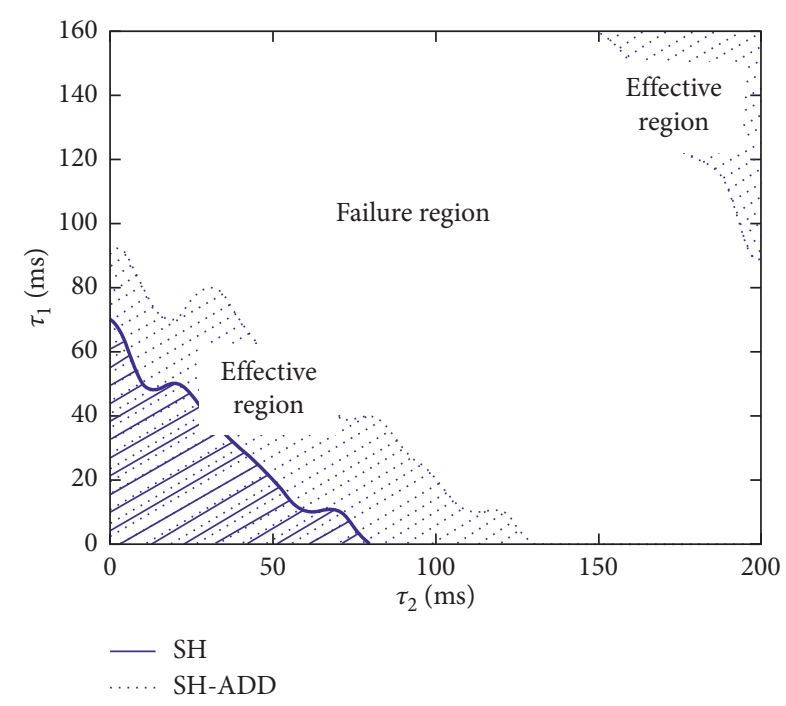

FIGURE 28: Time delay boundary curves of SH and SH-ADD controls when the velocity is $350 \mathrm{~km} / \mathrm{h}$.

From Figure 28, we observe that the permissible maximum collection time delay of SH control and SH-ADD control at $350 \mathrm{~km} / \mathrm{h}$ speed is $50 \mathrm{~ms}$ and $80 \mathrm{~ms}$, respectively. If execution time delay reaches to the time delay of the ordinary damper, then the permissible maximum collection time delay of SH control and SH-ADD control is only $30 \mathrm{~ms}$ and $70 \mathrm{~ms}$, respectively. From Figure 28, we also observe that semiactive control still plays a role if the value of collection time delay and execution time delay is large enough; it is indicated that the performance of the system can be improved by adopting feedback control with time delay in the real semiactive control system.

The relationship between collection time delay and execution time delay is very complicated. Considering the influence of them, the diagonal value of the matrix for the lateral ride index is the biggest, and the influence of collection time delay is higher than that of execution time delay. The value of the matrix is reduced gradually from the diagonal to two sides. In other words, with the increase of collection time delay or execution time delay, the trend of the lateral ride index increases at first and then decreases.

\section{Conclusion}

According to the difference of generation mechanism, the time delay is classified into collection time delay and execution time delay. Numerical simulation about the effect of two kinds of time delay are conducted based on the semiactive control system of the high-speed railway vehicle. According to the simulations and analyses, the following conclusions can be drawn:

(1) According to the different effects of collection time delay and execution time delay on system performance, take the effect of collection time delay as the row vector and the effect of execution time delay as the column vector. The effect of two kinds of time delay on the dynamic performance of the system can be drawn as $3 \mathrm{D}$ surfaces; there is a crossing curve between this surface and the plane of passive control; if we project this curve to the $X-Y$ plane, then the effective region of semiactive control under different control strategies can be drawn at last. If collection time delay and execution time delay lie in the effective region, it indicates that system performance can be improved using semiactive control; otherwise, the semiactive control is failure.

(2) With the increase in running speed for the highspeed railway vehicle, the time-delay robustness of semiactive controls is more and more weak. Compared with the ordinary damper, the MR damper has obvious advantages when considering the effect of time delay. These show that it is very important to analyze the effect of time delay on the railway vehicle under high speed and to adopt the MR damper with little time delay as a carrier of semiactive control.

(3) Against time delay ability of SH-ADD control is better than that of $\mathrm{SH}$ control; through adopting good performance semiactive control strategy, the permissible maximum time delay value of the system increases greatly and effectively improves the dynamic performance of the system.

\section{Data Availability}

The data used to support the findings of this study are available from the corresponding author upon request.

\section{Conflicts of Interest}

The authors declared no potential conflicts of interest with respect to the research, authorship, and/or publication of this article.

\section{Acknowledgments}

The authors thank the State Key Laboratory of Mechanical Behaviour in Traffic Engineering Structure and System Safety for providing equipment to the experiments. The authors disclosed receipt of the following financial support for the research, authorship, and/or publication of this article: National Natural Science Foundation of China (nos. 11790282, 11572206, and U1534204), the Natural Science Foundation of Hebei Province (no. A2016210099), the Talent Training Foundation Scientific Research Project of Hebei Province (no. A2016002036), and the Program for Advanced Talent in the Universities of Hebei Province (GCC2014021).

\section{References}

[1] W. H. Zhang, "The development of China's high-speed railway systems and a study of the dynamics of coupled systems in high-speed trains," Proceedings of the Institution of Mechanical Engineers, Part F: Journal of Rail and Rapid Transit, vol. 228, no. 4, pp. 367-377, 2014. 
[2] S. K. Sharma and A. Kumar, "Disturbance rejection and forcetracking controller of nonlinear lateral vibrations in passenger rail vehicle using magnetorheological fluid damper," Journal of Intelligent Material Systems and Structures, vol. 29, no. 2, pp. 279-297, 2018.

[3] Y. Yao, G. Wu, Y. Sardahi, and J.-Q. Sun, "Hunting stability analysis of high-speed train bogie under the frame lateral vibration active control," Vehicle System Dynamics, vol. 56, no. 2, pp. 297-318, 2018.

[4] S. K. Sharma and A. Kumar, "Ride performance of a high speed rail vehicle using controlled semi active suspension system," Smart Materials and Structures, vol. 26, no. 5, Article ID 055026, 2017.

[5] S. Sun, J. Yang, W. Li et al., "Development of a novel variable stiffness and damping magnetorheological fluid damper," Smart Materials and Structures, vol. 24, no. 8, Article ID 085021, 2015.

[6] W. G. Ata and A. M. Salem, "Semi-active control of tracked vehicle suspension incorporating magnetorheological dampers," Vehicle System Dynamics, vol. 55, no. 5, pp. 626-647, 2017.

[7] M. Biglarbegian, W. Melek, and F. Golnaraghi, "A novel neuro-fuzzy controller to enhance the performance of vehicle semi-active suspension systems," Vehicle System Dynamics, vol. 46, no. 8, pp. 691-711, 2008.

[8] Y. Sugahara, A. Kazato, R. Koganei, M. Sampei, and S. Nakaura, "Suppression of vertical bending and rigid-bodymode vibration in railway vehicle car body by primary and secondary suspension control: results of simulations and running tests using Shinkansen vehicle," Proceedings of the Institution of Mechanical Engineers, Part F: Journal of Rail and Rapid Transit, vol. 223, no. 6, pp. 517-531, 2009.

[9] H. C. Kim, Y. J. Shin, W. You et al., "A ride quality evaluation of a semi-active railway vehicle suspension system with MR damper: railway field tests," Proceedings of the Institution of Mechanical Engineers Part F Journal of Rail \& Rapid Transit, vol. 231, no. 3, pp. 517-531, 2017.

[10] S. K. Sharma and A. Kumar, "Ride comfort of a higher speed rail vehicle using a magnetorheological suspension system," Proceedings of the Institution of Mechanical Engineers, Part K: Journal of Multi-Body Dynamics, vol. 232, no. 1, pp. 32-48, 2018.

[11] H. Chen, C. Long, C.-C. Yuan, and H.-B. Jiang, "Non-linear modelling and control of semi-active suspensions with variable damping," Vehicle System Dynamics, vol. 51, no. 10, pp. 1568-1587, 2013.

[12] I.-K. Hwang, H.-M. Hur, M.-J. Kim, and T.-W. Park, "Analysis of the active control of steering bogies for the dynamic characteristics on real track conditions," Proceedings of the Institution of Mechanical Engineers, Part F: Journal of Rail and Rapid Transit, vol. 232, no. 3, pp. 722-733, 2018.

[13] H. R. O'Neill and G. D. Wale, Ride Improvements in a Railway Vehicle with a Semi-Active Suspension System, IET, Stevenage, UK, 2002.

[14] J.-S. Oh, Y.-J. Shin, H.-W. Koo, H.-C. Kim, J. Park, and S.-B. Choi, "Vibration control of a semi-active railway vehicle suspension with magneto-rheological dampers," Advances in Mechanical Engineering, vol. 8, no. 4, 2016.

[15] Y. K. Lau and W. H. Liao, "Design and analysis of magnetorheological dampers for train suspension," Proceedings of the Institution of Mechanical Engineers, Part F: Journal of Rail and Rapid Transit, vol. 219, no. 4, pp. 261-276, 2005.

[16] D. Karnopp, M. J. Crosby, and R. A. Harwood, "Vibration control using semi-active force generators," Journal of Engineering for Industry, vol. 96, no. 2, pp. 619-626, 1974.
[17] M. ValSek and M. Nova, "Ground hook for semi-active damping of truck's suspension," in Proceedings of the CTU Workshop 96, Engineering Mechanics, pp. 467-468, CTU Prague, Brno, Czech Republic, January 1996.

[18] R. Umehara, M. Otsuki, and K. Yoshida, "Bilinear robust control for vertical vibration in railway vehicle with semiactive suspensions," Journal of System Design and Dynamics, vol. 1, no. 1, pp. 2-13, 2007.

[19] S. M. Savaresi and C. Spelta, "Mixed sky-hook and ADD: approaching the filtering limits of a semi-active suspension," Journal of Dynamic Systems, Measurement, and Control, vol. 129, no. 4, pp. 382-392, 2007.

[20] B. F. Spencer, S. J. Dyke, M. K. Sain et al., "Idealized model of a magnetorheological damper," in Proceedings of the 12th Conference on Analysis and Computation, pp. 361-370, ASCE, Chicago, IL, USA, 1996.

[21] B. F. Spencer, "Recent trends in vibration control in the U.S.A.," in Proceedings of the 3rd International Conference on Motion and Vibration Control, Chiba, Japan, August 1996.

[22] C. Sakai, T. Terasawa, and A. Sano, "Integration of bilinear Ho control and adaptive inverse control for semi-active vibration isolation of structures," in Proceedings of the 44th IEEE Conference on Decision and Control, and the European Control Conference, pp. 5310-5316, CDC-ECC, Seville, Spain, December 2005.

[23] K. Sasaki and M. A. Nagai, "A lateral semi-active suspension of tilting train," in Proceedings of the International Symposium on Seed-Up and Service Technology for Railway and Maglev Systems (STECH'03), pp. 214-219, The Japan Society of Mechanical Engineers, Tokyo, Japan, August 2003.

[24] A. Yanik and U. Aldemir, "A simple structural control model for earthquake excited structures," Engineering Structures, vol. 182, pp. 79-88, 2019.

[25] D.-S. Huang, J.-Q. Zhang, and Y.-L. Liu, “The PID semi-active vibration control on nonlinear suspension system with time delay," International Journal of Intelligent Transportation Systems Research, vol. 16, no. 2, pp. 125-137, 2018.

[26] N. Eslaminasab, Development of a Semi-Active Intelligent Suspension System for Heavy Vehicles, University of Waterloo, Waterloo, Canada, 2008.

[27] N. Eslaminasab and M. F. Golnaraghi, "The effect of time delay of the semi-active dampers on the performance of on-off control schemes," in Proceedings of the 2007 ASME International Mechanical Engineering Congress and Exposition, Seattle, WA, USA, November 2007.

[28] Y. J. Cha, A. K. Agrawal, and S. J. Dyke, "Time delay effects on large-scale MR damper based semi-active control strategies," Smart Materials and Structures, vol. 22, no. 1, Article ID 015011, 2013.

[29] C. Spelta, S. M. Savaresi, and L. Fabbri, "Experimental analysis of a motorcycle semi-active rear suspension," Control Engineering Practice, vol. 18, no. 11, pp. 1239-1250, 2010.

[30] G. Simoneschi, C. Olivieri, A. M. de Leo, and A. Di Egidio, "Pole placement method to control the rocking motion of rigid blocks," Engineering Structures, vol. 167, pp. 39-47, 2018.

[31] Z. Li, I. Kolmanovsky, E. Atkins et al., "H-infinity filtering for cloud-aided semi-active suspension with delayed information," in Advances in Delays and Dynamics, pp. 283297, Springer, Cham, Switzerland, 2017.

[32] S. Sarami, Development and evaluation of a semi-active suspension system for full suspension tractors, Ph.D. thesis, University of Berlin, Berlin, Germany, 2009.

[33] National Standard of the People's Public of China (GB559985), Railway Vehicles-Specification for Evaluation the 
Dynamic Performance and Accreditation Test, National Bureau of standards of China, Beijing, China, 1985, in Chinese.

[34] Y. Q. Liu, Y. Y. Liao, S. P. Yang et al., "Effects of on-off semiactive control on dynamic performance of high-speed EMU," Zhendong Yu Chongji, vol. 35, no. 1, pp. 70-73, 2016, in Chinese.

[35] Y. Liu, S. Yang, and Y. Liao, "A Quantizing method for determination of controlled damping parameters of magnetorheological damper models," Journal of Intelligent Material Systems and Structures, vol. 22, no. 18, pp. 2127-2136, 2011. 


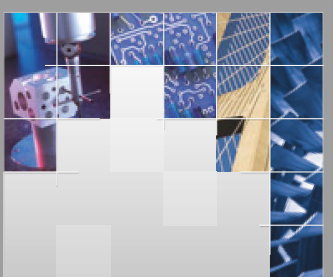

\section{Enfincering}
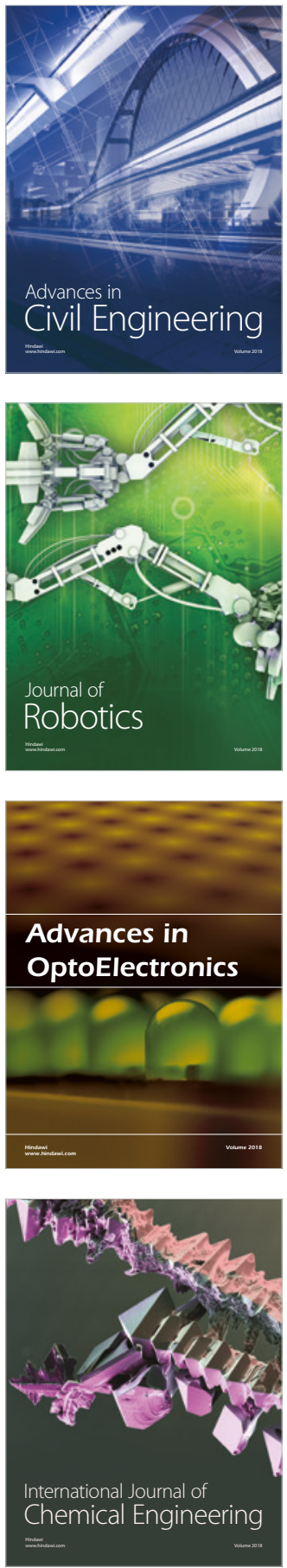

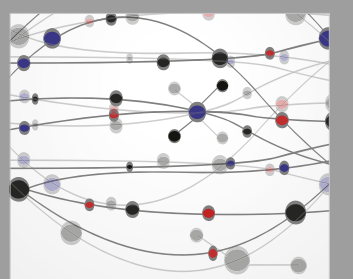

\section{Rotating \\ Machinery}

The Scientific World Journal

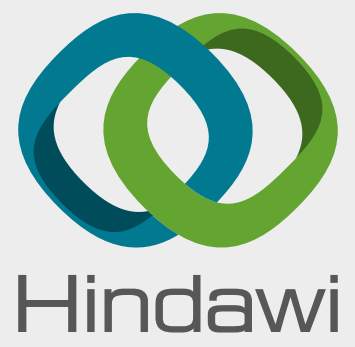

Submit your manuscripts at

www.hindawi.com
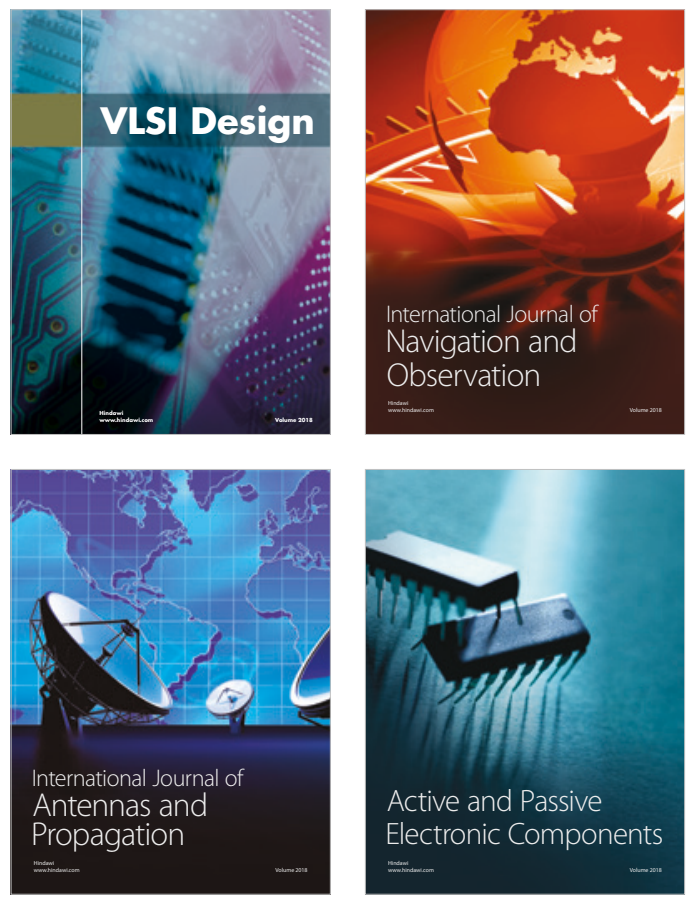
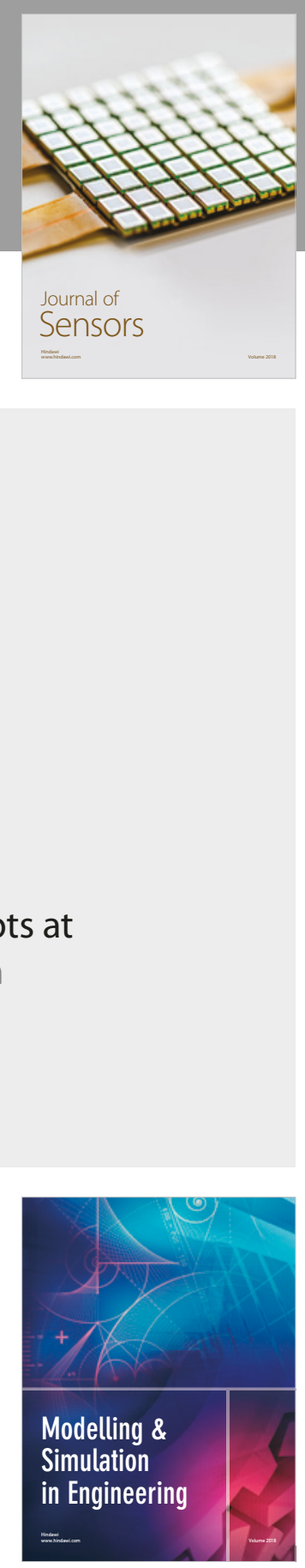

\section{Advances \\ Multimedia}
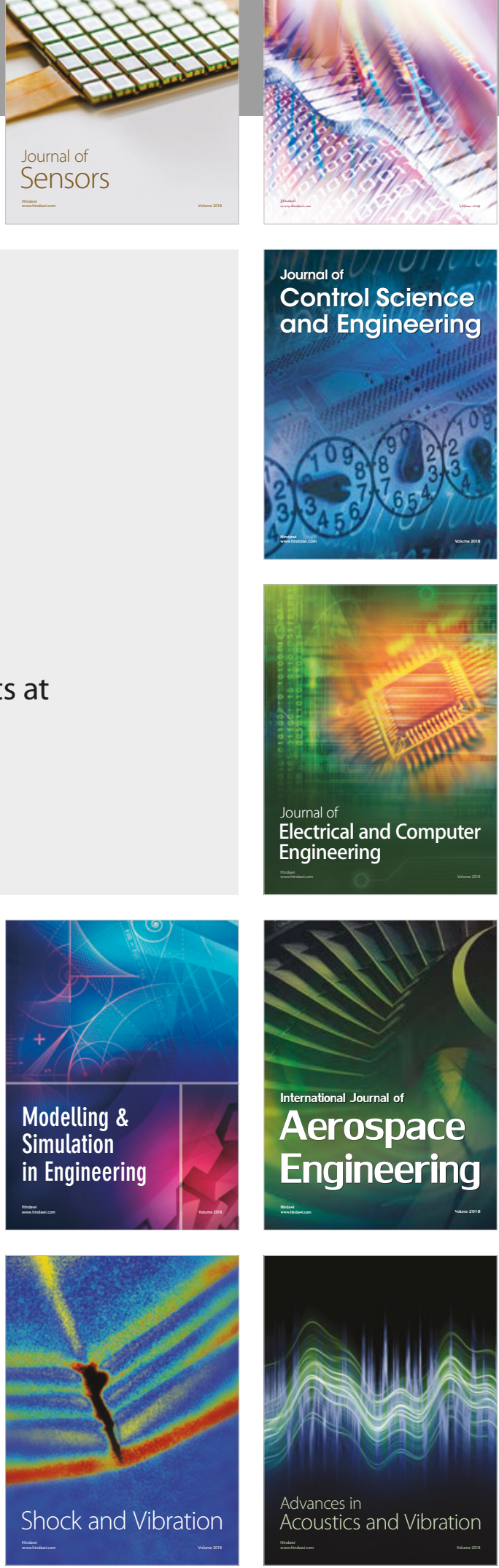